\title{
Seasonal variations and co-occurrence networks of bacterial communities in the water and sediment of artificial habitat in Laoshan Bay, China
}

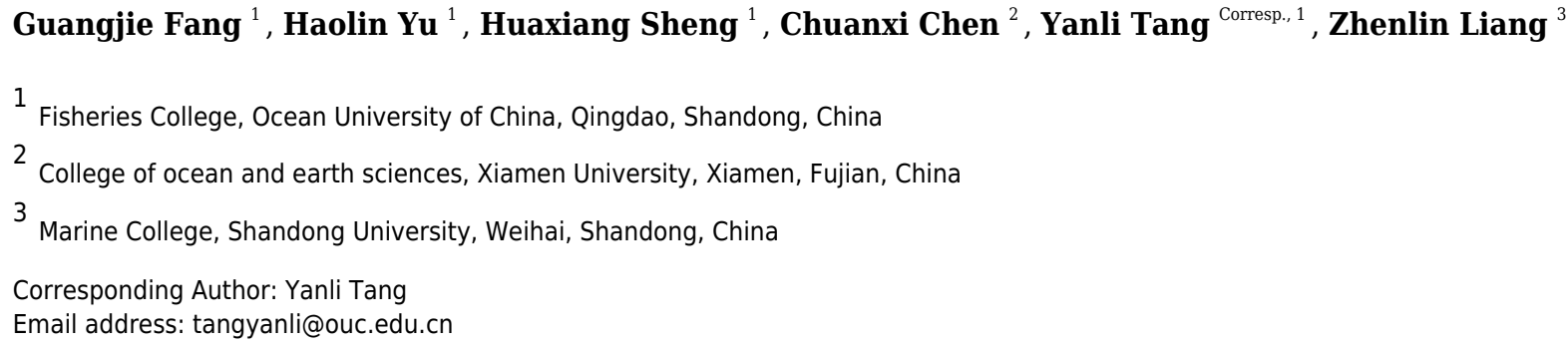

Marine bacteria in the seawater and seafloor are essential parts of Earth's biodiversity, as they are critical participants of the global energy flow and the material cycles. However, their spatial-temporal variations and potential interactions among varied biotopes in artificial habitat are poorly understood. In this study, we profiled the variations of bacterial communities among seasons and areas in the water and sediment of artificial reefs using 16S rRNA gene sequencing, and analyzed the potential interaction patterns among microorganisms. Distinct bacterial community structures in the two biotopes were exhibited. The Shannon diversity and the richness of phyla in the sediment were higher, while the differences among the four seasons were more evident in the water samples. The seasonal variations of bacterial communities in the water were more distinct, while significant variations among four areas were only observed in the sediment. Correlation analysis revealed that nitrite and mud content were the most important factors influencing the abundant OTUs in the water and sediment, respectively. Potential interactions and keystone species were identified based on the three co-occurrence networks. Results showed that the correlations among bacterial communities in the sediment were lower than in the water. Besides, the abundance of the top five abundant species and five keystone species had different changing patterns among four seasons and four areas. These results enriched our understanding of the microbial structures, dynamics, and interactions of microbial communities in artificial habitats, which could provide new insights into planning, constructing and managing these special habitats in the future. 
1 Seasonal variations and co-occurrence networks of

2 bacterial communities in the water and sediment of

3 artificial habitat in Laoshan Bay, China

4

5 6

$7 \quad{ }^{1}$ Fisheries College, Ocean University of China, Qingdao, Shandong, China

$8{ }^{2}$ College of Ocean and Earth Sciences, Xiamen University, Xiamen, Fujian, China

$9{ }^{3}$ Marine College, Shandong University, Weihai, Shandong, China

10

11

12

13

14

15

16

17

Corresponding Author:

Yanli Tang

3 Fisheries College, Ocean University of China, No.5, Yushan Road, Qingdao, Shandong, 266003, China

Email address: tangyanli@ouc.edu.cn 


\section{Abstract}

19 Marine bacteria in the seawater and seafloor are essential parts of Earth's biodiversity, as they are

20 critical participants of the global energy flow and the material cycles. However, their spatial-

21 temporal variations and potential interactions among varied biotopes in artificial habitat are

22 poorly understood. In this study, we profiled the variations of bacterial communities among

23 seasons and areas in the water and sediment of artificial reefs using 16S rRNA gene sequencing,

24 and analyzed the potential interaction patterns among microorganisms. Distinct bacterial

25 community structures in the two biotopes were exhibited. The Shannon diversity and the richness

26 of phyla in the sediment were higher, while the differences among the four seasons were more

27 evident in the water samples. The seasonal variations of bacterial communities in the water were

28 more distinct, while significant variations among four areas were only observed in the sediment.

29 Correlation analysis revealed that nitrite and mud content were the most important factors

30 influencing the abundant OTUs in the water and sediment, respectively. Potential interactions and

31 keystone species were identified based on the three co-occurrence networks. Results showed that

32 the correlations among bacterial communities in the sediment were lower than in the water.

33 Besides, the abundance of the top five abundant species and five keystone species had different

34 changing patterns among four seasons and four areas. These results enriched our understanding

35 of the microbial structures, dynamics, and interactions of microbial communities in artificial

36 habitats, which could provide new insights into planning, constructing and managing these

37 special habitats in the future.

38 Keywords: Marine biodiversity, Habitat degradation, Artificial reefs, Potential interaction,

39 Keystone species

40

\section{Introduction}


42 Global marine biodiversity is threatened by habitat degradation, environmental pollution,

43 overexploitation, and other anthropogenic disturbances (Timothy et al., 2006; Pereira et al., 2010;

44 Todd et al., 2019). The decline of global biodiversity has resulted in changes in marine ecosystem

45 structures (Verity et al., 2002). In the coastal waters, habitat loss and degradation are especially

46 tricky problems that must be faced (Jackson et al., 2001; Koldewey et al., 2010). To recover

47 marine habitats that provide feeding, spawning grounds, and shelters, artificial habitats are

48 constructed to support the functions of coastal ecosystems (Janiak and Branson, 2021). Artificial

49 reefs (ARs) offer a series of ecological services like improving marine habitats, increasing fishery

50 resources, and manipulating assemblages of ocean organisms (Seaman and Sprague, 1993; Lima

51 et al., 2019), which is an important form of artificial habitat in marine fisheries. ARs facilitate

52 biological production and enhance fishery resources by creating additional habitats for marine

53 organisms (Ng et al., 2017). At present, ARs have been deployed worldwide by creating different

54 structures related to fishing, scuba diving and coastal recreation (Lima et al., 2019). In China, the

55 practice of deploying ARs to create artificial habitats has been proposed by the government since

56 the 1970s (Sun et al., 2017). The annual investment in ARs is about 100 million dollars in recent

57 years, and its primary purposes are conserving marine environment, enhancing fishery resources,

58 and developing recreational fishing (Yang et al., 2019; Xu et al., 2021). With the increasing

59 attention to ARs, most studies have focused on the behaviors of targeted species (Williams-Grove

60 and Szedlmayer, 2017), designs and engineering (Woo et al., 2014), ecological impacts (Shin et

61 al., 2014), fishery management (Lima et al., 2020) and others (Chen et al., 2013). However, few

62 studies focused on the bacterial community structure in ARs.

63 Microorganisms in marine ecosystems play crucial roles in global biogeochemical processes,

64 such as energy flow, carbon and nutrient cycles (Steele et al., 2011; Sunagawa et al., 2015).

65 Therefore, recognizing that the functions of microbial communities are essential to master the

66 restoration mechanism of artificial habitats. Scientific attempts have been made to isolate and 
67 characterize particular microbiomes to explain the ecological roles of artificial habitats in the

68 1990s (Zentgraf et al., 1992). Then, the dynamics of bacterial communities associated with coral

69 reefs (natural habitats) and artificial habitats were compared to verify the ecological effects of

70 two habitats using terminal restriction fragment length polymorphisms (Soka et al., 2011).

71 Nowadays, high-throughput sequencing has dramatically facilitated the understanding of the

72 mechanisms of marine microbial ecology (Langille et al., 2013). Despite great advancements,

73 studies paying attention to the bacterial communities in the water and sediment of ARs are

74 limited. Wang et al. (2019c) assessed the impact of ARs on bacterial communities in the sediment

75 to reveal the changes of microbial structure and functions. Qin et al. (2019) and Zhu et al. (2020)

76 studied the shifts of community dynamics and interaction patterns of the protists in Daya Bay

77 after the deployment of ARs.

78 Microbial community dynamics have been observed at different time scales, from days

79 (Mangot et al., 2013), weeks (Berdjeb et al., 2018), months (Marquardt et al., 2016) to seasons

80 (Genitsaris et al., 2015), and years (Boras et al., 2010). Apart from seasonality, habitats are

81 important factors that influence microbial communities (Sun et al., 2019), especially between

82 water and sediment (Abia et al., 2017; Liu et al., 2018). After profiling the structures and

83 dynamics of microbial communities, co-occurrence network is a powerful tool to uncover the

84 potential ecological interactions among microorganisms (Barberan et al., 2012), and have been

85 applied to obtain a more integrated understanding of microbial communities (Mikhailov et al.,

86 2019; Zhang et al., 2020a).

87 Laoshan Bay is a representative semi-enclosed bay in northern China, with an area of

88 approximately $188 \mathrm{~km}^{2}$. Laoshan Bay is an important marine culture area for sea cucumber

89 (Apostichopus japonicus) and oyster (Crassostrea gigas), and is a stock enhancement area for

90 shrimp and fish species (Sheng et al., 2018). The annual mean seawater temperature is

91 approximately $15^{\circ} \mathrm{C}$ and has significant seasonal changes $\left(5^{\circ} \mathrm{C}-25^{\circ} \mathrm{C}\right.$; Wang et al., 2019b). 
92 Fishery resources in Laoshan Bay have decreased rapidly because of habitat degradation and

93 overexploitation. To help reproductive success and support recruitment, two types of ARs were

94 deployed since 2005: (1) rock reefs were deployed with mean volumes of at least $0.04 \mathrm{~m}^{3}$ (weight

$95100 \mathrm{~kg}$ ); (2) concrete reefs were arranged with principal dimensions of $2 \mathrm{~m} \times 2 \mathrm{~m} \times 2 \mathrm{~m}$.

96 For decades, ARs have been deployed worldwide around coasts to recover marine habitats, and

97 the ecological effects of ARs have been evaluated through periphytons, plankton, benthos, and

98 nekton (Aleksandrov et al., 2002; Scott et al., 2015; Ng et al., 2017; Chen et al., 2019). However,

99 few studies have examined the microbial communities. This study elucidated the bacterial

100 communities in the water and sediment of artificial habitat with two types of ARs using 16S

101 rRNA gene sequencing. The major objectives were: (1) to provide a comprehensive

102 understanding of the bacterial community structures and dynamics in the water and sediment of

103 ARs, (2) to reveal the influence of environmental factors on bacterial communities in the water

104 and sediment, respectively, and (3) to analyze the potential interactions among bacteria and

105 identify the keystone taxa in the ARs.

106

107 Materials and Methods

108 Study sites and sample collection

109 Triplicate water and sediment samples were collected from Laoshan Bay ARs in January

110 (winter), May (spring), August (summer), and November (autumn), 2020 (Fig. S1). Ninety-six

111 samples from four sampling areas were studied: rock reefs (RR), transition areas (TA), concrete

112 reefs (CR) and adjacent areas (AA). For the water samples, we used a plexiglass to collect $2 \mathrm{~L}$

113 bottom water at every sampling area. For the sediment samples, grab sediment sampler was

114 applied to get about $1 \mathrm{~kg}$ surface sediment $(0-10 \mathrm{~cm})$ for analysis. Water and sediment samples

115 were stored at a cooler filled with ice and immediately transported back to the laboratory in two

116 hours. The methods for treating samples were followed as previously described in Fang et al. 
117 (2021). All field experiment was permitted by "Measures for annual evaluation and

118 reexamination of national marine ranching demonstration areas”, which was promulgated by

119 Ministry of agriculture and rural areas of China.

\section{Measurements of environmental factors}

121 The temperature (Temp), dissolved oxygen (DO), chlorophyll-a (Chla), sampling depth (Dep),

$122 \mathrm{pH}$ and salinity (Sal) of water samples were measured in situ using a YSI PRODSS multi-

123 parameter water quality analyzer (YSI, USA). Transparency (Trans) was obtained by a Secchi

124 disk. The turbidity (Turb) of each area was determined by a Turb 430 IR (Xylem Analytics,

125 Germany). The determination of the total organic carbon (TOC) was performed through a TOC-L

126 series total organic carbon analyzer (Shimadzu, Japan). Eight water environmental factor,

127 including suspended particulate materials (SPM), particulate organic matter (POM), chemical

128 oxygen demand (COD), ammonium $\left(\mathrm{NH}_{4}-\mathrm{N}\right)$, nitrate $\left(\mathrm{NO}_{3}-\mathrm{N}\right)$, nitrite $\left(\mathrm{NO}_{2}-\mathrm{N}\right)$, active silicate

$129\left(\mathrm{SiO}_{3}\right)$ and active phosphate $\left(\mathrm{PO}_{4}\right)$ were analyzed under the guidance of GB/T 12763-2007 (State

130 Bureau of Quality and Technical Supervision of China, 2007).

131 For the measurement of sediment characteristics, Mastersizer 3000 (Malvern, UK) was applied

132 to measure the mean particle sizes (Par). Sediment bulk density (BD) was defined as the dry

133 weight of the sediment (drying at $105^{\circ} \mathrm{C}$ for $72 \mathrm{~h}$ ) divided by the wet volumes. Water content

134 (WC) was the weight proportion of water in the sediment (drying at $70^{\circ} \mathrm{C}$ for $72 \mathrm{~h}$ ). After burning

135 the sediment to ash totally $\left(550^{\circ} \mathrm{C}\right.$ for $\left.4 \mathrm{~h}\right)$, organic matter content (OM) was obtained. The

136 method for mud content (MC, dry sediment) was following Eleftheriou (2013). As for the salinity

137 (Sal), electrical conductivity (EC) and $\mathrm{pH}$ of the sediment, a mixture of sediment and deionized

138 water (2:5, w/v) was used.

139 DNA extraction, PCR amplification, Illumina MiSeq sequencing and Sequence analysis

140 Genomic DNA of the whole samples was extracted using the FastDNA ${ }^{\circledR}$ SPIN Kit for Soil (MP

141 Biomedicals, Irvine, CA, USA) according to the manufacturer's instructions. Specifically, the 
142 universal primers 338F (5'-ACTCCTACGGGAGGCAGCAG-3') and 806R (5'-

143 GGACTACHVGGGTWTCTAAT-3') were used, which amplified 468 bp in V3-V4

144 hypervariable region of 16S rRNA gene. The procedures of the PCR amplification was based on

145 the manufacturer's instructions and the standard protocols of Majorbio Bio-Pharm Technology

146 Co. Ltd. (Shanghai, China). Raw sequence reads were analyzed using QIIME 1.9 (Caporaso et

147 al., 2010). The detailed processes were all described in Supp. File 1. The sequencing data have

148 been deposited in the National Center for Biotechnology Information (NCBI) Sequence Read

149 Archive database under the accession number PRJNA725051.

\section{Statistical analysis}

151 The number of OTUs and alpha diversity estimators (Shannon, Simpson, Ace, Chao 1 and

152 Good's coverage) were analyzed among four seasons and two habitats. The seasonal and spatial

153 variations of bacterial community compositions were compared by principal coordinate analysis

154 (PCoA) based on the Bray-Curtis distance matrix (Borcard et al., 2011). The effects of the

155 temporal and spatial factors on the bacterial communities were tested using permutation

156 multivariate analysis of variance (PERMANOVA) and analysis of similarity (ANOSIM)

157 (Anderson, 2001; Clarke, 1993). Statistical differences were analyzed using the Kruskal-Wallis

158 test, and the differences were considered significant at $P<0.05$. The correlations between the

159 most abundant OTUs (relative abundance > 0.5\%) and environmental factors, sampling areas

160 were determined by Spearman correlation analysis, and the visualization was achieved by

161 heatmaps (Borcard et al., 2011). The impacts of environmental factors on bacterial communities

162 were evaluated by the Mantel test and partial Mantel test (Smouse et al., 1986). Statistical

163 analyses were conducted in R 4.0.2 using the "phyloseq" and "vegan” packages (www.r-

164 project.org).

165 The visualization of the three co-occurrence networks was built using Cytoscape 3.8.2

166 (www.cytoscape.org) for the all bacterial communities in the water, sediment and both two 
167 habitats. To improve the visibility and sensitivity of the networks, OTUs observed in more than

$16850 \%$ of all samples and the mean relative abundance higher than $0.5 \%$ were selected. Then, we

169 calculated the Spearman correlations and significances between OTUs in R. Significant edges ( $P$

$170<0.001)$ with high correlations $(|\mathrm{r}|>0.8)$ were chose to construct the co-occurrence networks.

171 The network topology parameters were calculated using the Analyze Network plugin of

172 Cytoscape to identify the keystone OTUs in the networks (Cheung et al., 2018). Three topology

173 parameters were: (1) degree: the number of edges that a node has; (2) betweenness centrality: the

174 number of shortest paths between any two nodes in the graph passing through a node; (3)

175 closeness centrality: the average distance of a node to any other node. After that, min-max scaling

176 was applied to standardize degree, 1-betweenness centrality, and closeness centrality,

177 respectively. Last, keystoneness was defined as the average of degree, 1-betweenness centrality,

178 and closeness centrality after min-max scaling was calculated (Berry and Widder, 2014); and the

179 top 10 OTUs with highest scores were identified as the keystone species (Cheung et al., 2018).

180 Jaccard index was applied to analyze the similarities of OTUs among networks (Dmitry et al., 181 2016).

182

183 Results

\section{Bacterial alpha diversities and community compositions}

185 A total of 5,427,513 high-quality bacterial 16S rRNA gene sequences and 17,207 OTUs with 186 97\% similarity levels were identified from 96 water and sediment samples. Sediment samples

187 (15,010 OTUs) had higher OTUs than water samples (9,423 OTUs), and 7,226 OTUs were

188 shared between the two habitats. The Good's coverage was over $90 \%$ in all samples, indicating

189 the current sequencing depth was sufficient for this study. Alpha diversity indices showed

190 significant variations between the habitats and seasons (Table 1), while there were no differences

191 among four areas. The diversity indices (Shannon, Chao 1 and Ace) of water samples were 
192 significantly lower than sediment, while the diversity indices (Simpson and Good's coverage) of

193 water were higher (Table 1). A seasonal pattern of alpha diversity indices (e.g., Shannon) could

194 be observed in the water samples, which varied from 4.09 to 5.16 (Fig. 1). However, no

195 significant seasonal differences were found in the sediment except for the Simpson diversity

196 index (Table 1).

197 Seasonal variations of the abundant phyla in the water were more evident than sediment, but

198 the differences among the four areas were low. The total abundance of the three most abundant

199 phyla was over 74\% and around 50\% for water and sediment samples, respectively. For the water

200 samples, the three most abundant phyla (> 10\%) were Proteobacteria, Cyanobacteria, and

201 Actinobacteria, with mean relative abundances of 42.8\%, 18.3\% and 13.1\%, respectively (Fig. 2).

202 Marked seasonal changes were observed in many bacterial phyla. The phylum Proteobacteria had

203 a relative abundance greater than $56.8 \%$ in autumn, while its abundance was $23.6 \%$ in summer;

204 the phyla Actinobacteria and Cyanobacteria had the highest abundances in summer (20.9\% and

205 29.4\%) and the lowest abundances in winter (6.6\% and 13.2\%). In the sediment, the bacterial

206 community was dominated (> 10\%) by the phyla Proteobacteria, Desulfobacterota, and

207 Acidobacteria, which comprised approximately $28.4 \%, 10.8 \%$, and $10.2 \%$ of the relative

208 abundances, respectively (Fig. 2). The relative abundance of the phylum Chloroflexi (mean

209 abundance was 8.6\%, ranked 4th) had marked seasonal changes, whose abundance in autumn

210 (12.0\%) was twice that in winter (6.7\%).

\section{Bacterial community structure}

212 Two different bacterial groups were observed between the water and sediment samples (Fig. 3;

213 Table 2). Significant seasonal differences were both observed for the water and sediment

214 samples, and the bacterial communities in the water samples were more divergent and separated

215 than sediment (Fig. S2). The bacterial communities in the sediment varied among seasons, areas,

216 and their interactions based on PERMANOVA and ANOSIM (Table 2). However, there was no 
217 significant difference among the four areas in the water. The Bray-Curtis dissimilarities among

218 four areas had similar seasonal changing trends in the two habitats; and the dissimilarities were

219 highest in autumn and lowest in summer (Fig. 4). The top 39 abundant water OTUs and 24

220 sediment OTUs (> 5\%o), which affiliated to six and thirteen bacterial classes, showed varying

221 abundances among four areas (Fig. S3). According to the results of cluster trees, bacterial

222 communities in the areas RR and TA were different from areas CR and AA in the water samples

223 (Fig. S3a); communities in the area CR was separate from other three areas in the sediment (Fig.

224 S3b).

\section{Relationships between abundant OTUs and environmental factors}

226 The relationships among bacterial communities and environmental factors were significant both

227 in the water and sediment samples based on the Mantel test (Table 3, Table S1). For the water

228 samples, $\mathrm{NO}_{2}-\mathrm{N}(\mathrm{r}=0.414)$ was the most correlating factor in shaping the community; Temp,

229 Trans, $\mathrm{PO}_{4}, \mathrm{DO}, \mathrm{SiO}_{3}$, and COD were significant correlating factors. In the sediment, $\mathrm{MC}(\mathrm{r}=$

230 0.125) was the only factor that significantly impacted the bacterial community. The relative

231 abundances of the top abundant OTUs were noticeably related to the environmental factors (Fig.

232 5). For the water samples, thirty-three OTUs were significantly correlated with Temp, while only

233 two OTUs were related to Chla (Fig. 5a). For the sediment samples, thirteen OTUs were highly

234 related to EC, and four OTUs were related to WC and OM (Fig. 5b). Also, two bacterial groups

235 were observed that responded to the environmental factors, conversely. For example, class

236 Gammaproteobacteria and class Alphaproteobacteria were divided into two groups for the

237 sediment samples, correspondingly.

238 Co-occurrence networks and keystone species

239 One co-occurrence network containing total bacteria both in the water and sediment, and two

240 networks for the communities in the water and sediment, were constructed to analyze the

241 connections, stability, and complexity of bacterial communities in the ARs (Fig. 6; Fig. S4 and 
242 Fig. S5). For the total bacteria network, 185 nodes belonging to 18 phyla and 6,832 edges were

243 detected. A complete distinction of nodes from water and sediment samples formed two modules

244 (Fig. 6a). The most abundant OTUs (top five OTUs with highest abundance) in the network were

245 OTU18562 (Firmicutes), OTU18460 (Cyanobacteria), OTU10090 (Proteobacteria), OTU17592

246 (Proteobacteria), and OTU18751 (Actinobacteria). Four OTUs mainly from water samples

247 exhibited seasonal variations in their abundances; OTU10090 was from sediment samples, which

248 had no seasonal change (Fig. 7a). Differences of five abundant OTUs among four areas were not

249 significant except OTU18562 (Fig. 8a). The bacterial network for the water samples comprised

250189 nodes belonging to 15 phyla, while only 1,772 edges were observed (Fig. S4). OTU18562

251 (Firmicutes), OTU14763 (Cyanobacteria), OTU17592 (Proteobacteria), OTU18751

252 (Actinobacteriota), and OTU18053 (Proteobacteria) had the highest abundances in the network.

253 Similar seasonal changes of OTU18562 and OTU17592 in abundance were observed, and the

254 other three OTUs showed similar trends (Fig. 7b). OTU18562 showed a most apparent difference

255 among four areas compared with other four abundant OTUs (Fig. 8b). For the sediment bacterial

256 network, 274 nodes belonging to 24 phyla and 1,166 edges were observed (Fig. S5). The top five

257 most abundant OTUs in this network were OTU10090 (Proteobacteria), OTU3621

258 (Desulfobacterota), OTU13814 (Myxococcota), OTU13137 (Desulfobacterota), and OTU6550

259 (Chloroflexi). The seasonal variations of the five OTUs were not evident (Fig. 7c), and

260 OTU10090 showed lower abundances in areas RR and CR than in TA and AA (Fig. 8c).

261 The top keystone OTUs with relative abundances higher than 1\%o were identified as the

262 keystone taxa in the co-occurrence networks. In the total bacterial co-occurrence network, the top

26310 keystone OTUs were affiliated to five phyla, Myxococcota, Proteobacteria,

264 Gemmatimonadota, Chloroflexi and Actinobacteriota (Table S2a). The keystone OTU with

265 highest keystoneness was OTU13814 (Myxococcota, keystoneness = 0.840), which ranked 15

266 among all OTUs with a relative abundance of 12.3\%; the abundance of OTU12321 
267 (Proteobacteria, keystoneness $=0.836$ ) ranked 150 with a relative abundance of $1.8 \%$. There was

268 no significant seasonal abundance variation for the top five keystone OTUs except OTU13814,

269 and no evident differences among the four areas were found (Fig. S6a, S7a). For the water

270 network, the top 10 keystone OTUs included members of the phyla Bacteroidota, Proteobacteria,

271 Desulfobacterota, Gemmatimonadota and Acidobacteriota (Table S2a). The top two keystone

272 OTUs (OTU525 and OTU7969) had abundances of 2.3\%o (ranked 90) and 1.4\%o (ranked 123),

273 respectively. Similar seasonal trends of the abundance for the top five keystone OTUs were

274 observed, which showed higher abundance in spring and autumn (Fig. S6b). For the sediment

275 network, the top 10 keystone OTUs belonged to three phyla, Proteobacteria, Firmicutes and

276 Chloroflexi (Table S2c). OTU6991 (abundance 2.3\%o, ranked 114) and OTU3902 (abundance

277 8.8\%o, ranked 24) were the only two keystone OTU with keystoneness greater than 0.7. The

278 changing patterns among the four seasons and four areas for keystone OTU17592, OTU16870,

279 and OTU17616 were consistent (Fig. S6c and Fig. S7c).

280

281 Discussion

282

\section{Bacterial community characteristics in the water and sediment of ARs}

283 The distributions of the marine bacterial communities were highly of indigenous and specific,

284 while the abundant taxa that represented in the communities were analogous (Pommier et al.,

285 2007). In this study, Proteobacteria, Cyanobacteria, and Actinobacteria were the most abundant

286 phyla, with a total relative abundance of $74 \%$ in the water samples (Fig. 2), which was consistent

287 with previous studies in coastal waters (Lee and Eom, 2016; Ye et al., 2016). For the differences

288 of bacterial communities between habitats, sixteen shared phyla were observed between the water

289 and sediment, and five phyla among sixteen phyla had higher relative abundances in the water

290 than those in the sediment. The absolute predominance of the phylum Proteobacteria in the water

291 samples may be the main reason. Because of the higher abundance of Proteobacteria (42.8\%) in 
292 the water samples, significantly restricting the population size of the other bacterial phyla (e.g.,

293 Sun et al., 2019). Higher diversities of the bacterial communities were observed in the sediment

294 than water (Fig. 1; Table 1), which was in accordance with the results of Feng et al. (2009) and

295 Abia et al. (2017). Some reasonable assumptions were proposed. Ye et al. (2009) stated that

296 sediments within aquatic environments formed more complex environments, which resulted in

297 more prosperous bacterial communities; Perkins et al. (2014) noted that sediment provided

298 shelters for bacteria, which helped to defend against the impacts of predation and sunlight; Liu et

299 al. (2018) explained that lower concentration of suspended sediment in the water would lead to

300 lower microbial diversity.

301 The heatmap of the abundant OTUs with four areas revealed that bacterial abundance in RR

302 was inconsistent with other areas, especially in the sediment (Fig. S3). Many studies showed that

303 the diet preference of A. japonicus can change the microbial communities in the sediment (e.g.,

304 Zhao et al., 2020). Thus, we assumed that the aquaculture activities of $A$. japonicus in RR might

305 result in these distinctions. Besides, rock reefs were deployed more intensive than concrete reefs,

306 changing the substrate and flow field surrounding ARs more significantly (e.g. Tang et al., 2022),

307 which might impact the bacterial communities strongly. As for the differences of bacterial

308 abundance among four areas, some inconsistencies were observed. For instance, OTU1283

309 (Actinobacteriota) showed significantly higher abundance in RR and CR than that in TA and AA,

310 which suggested that it favored ARs. The phylum Actinobacteria plays important roles in

311 mineralizing organic matter in marine sediment (Bell et al., 1998), indicating that the organic

312 matter content in the ARs was higher than that in non-intervened areas. OTU7413 (family

313 Rhodobacteraceae) was regarded as an important food resource for A. japonicus (Zhao et al.,

314 2020), which showed a lower abundance in RR than other three areas.

315 As for the beta diversity among the four areas, the highest and lowest beta diversities were

316 found in autumn and summer, respectively (Fig. 4). Some current studies highlighted that high 
317 beta diversity of bacterial communities in a particular season was a response to environmental

318 heterogeneity (Fournier et al., 2020). While some studies addressed that the Bray-Curtis

319 dissimilarities among microbial communities did not significantly correlated with environmental

320 factors such as temperature and salinity (Balzano et al., 2015). These opposite conclusions may

321 result from the differences in spatial and temporal scales (Hatosy et al., 2013).

\section{Seasonal dynamics of bacterial communities in ARs}

323 Marine bacterioplankton exhibit pronounced seasonal succession patterns worldwide (Bunse and

324 Pinhassi, 2017), and follow with the changes of temperature, chlorophyll-a, and other nutrients

325 (Mohapatra et al., 2020; Pinhassi et al., 2006). In this study, seasonal changes in the relative

326 abundances of diversity indices, abundant species and community structures were observed. The

327 seasonal variations of $\alpha$ diversity between water and sediment were inconsistent (Fig. 1). In the

328 water samples, a more considerable fluctuation of $\alpha$ diversity was observed, and had the highest

329 Shannon diversity in spring. Similar seasonal patterns in the Shannon diversity have been

330 observed in other seawaters (Piwosz et al., 2018; Zhu et al., 2020). Previous studies indicated that

331 sudden decrease of microbial plankton communities in winter and new growing season in spring

332 preceding the spring bloom (Espinoza-González et al., 2012; Figueiras et al., 2020) could

333 promote these seasonal patterns. Therefore, higher diversity in spring can be explained by the

334 intrinsically high growth rate of bacterioplankton (Agawin et al., 2000). However, no significant

335 differences of bacterial diversity in the sediment were detected. Marine sediment is characterized

336 as a habitat type with high biodiversity, complicated community structures and spatial

337 heterogeneity (Brandt et al., 2016). The bacterial communities in the sediment had wider niche

338 ranges and sufficient nutrients, which helped maintain and facilitate prosperous diversities (Shu

339 et al., 2020).

340 The abundance of the abundant phyla also showed conspicuous varieties (Fig. 2). For the water

341 samples, our results showed that Actinobacteria had the highest abundance in summer, when the 
342 salinity was lowest because of higher precipitation level. Shen et al. (2018) confirmed that

343 Actinobacteria is sensitive to the change of salinity. Meantime, the peak abundance of

344 Cyanobacteria occurred in summer. Martin et al. (2017) also stated that the autotrophic

345 Cyanobacterium, Synechococcus exhibited higher abundances during monsoons. For the

346 sediment samples, the seasonal variations of the abundant bacteria were not significant compared

347 with water samples. For instance, Chloroflexi was the most abundant in autumn. Chloroflexi is

348 regarded as having anaerobic and heterotrophic lifestyles, which are positively related to organic

349 matters (Wilms et al., 2006). In autumn, the seaweed cultivation in the adjacent sea could

350 probably explain their higher abundances of Chloroflexi.

351 Marked seasonality of bacterial community compositions in the water was widely observed.

352 Shu et al. (2020) found distinct seasonal patterns of core and non-core bacterial communities in

353 an urban river; Mohapatra et al. (2020) discovered that seasonal variations of environmental

354 drivers highly impacted the bacterial communities. However, the seasonal variations of microbial

355 community compositions in the sediment were controversial. We observed significant seasonal

356 changes of bacterial communities at OTU level (Table 2), while some similar studies have

357 presented different conclusions. Liu et al. (2015) revealed noticeable seasonal variations of

358 bacteria community because of environmental heterogeneity; Palit and Das (2020) reported a

359 comparatively low seasonal fluctuation of sediment bacterial communities in part of sampling

360 sites based on the culture-dependent method; Ming et al. (2021) indicated that no marked

361 seasonal difference was observed among the bacterial community compositions. Different

362 temporal and spatial scales may cause these inconsistent results, and more follow-up studies are

363 suggested.

\section{Environmental characteristics and bacterial communities}

365 Environmental factors significantly affected bacterial communities, such as nitrite, temperature in

366 the water (Fadeev et al., 2018; Zorz et al., 2019) and mud content in the sediment (Lee et al., 
367 2020). In the present study, the Mantel test revealed that nitrite, temperature, and transparency

368 significantly correlated with the communities in the water, while mud content was the only

369 related factor in the sediment (Table 3). Although $\mathrm{N}$ and $\mathrm{P}$ are limiting factors of eutrophication,

370 they are important nutrients affecting the proliferation of bacteria (Huang et al., 2017). Our

371 results revealed that dissolved inorganic nitrogen $\left(\mathrm{NO}_{3}-\mathrm{N}, \mathrm{NH}_{4}-\mathrm{N}, \mathrm{NO}_{2}-\mathrm{N}\right)$ was correlated with

372 many abundant OTUs (Fig. 5a). Water temperature is an important factor that governs microbial

373 growth and activity (Margesin, 2009), and thirty-three abundant OTUs were significantly related

374 to temperature. Light intensity could also shape different microbial communities (Davies and

375 Evison, 1991), and our studies confirmed that the correlation between transparency and the

376 bacterial communities was significant. Different electrical conductivity levels can influence

377 bacteria (Silverman and Munoz, 1975), which was in accordance with the results that the

378 abundances of thirteen dominant OTUs were affected by EC. Mud content was a vital factor

379 influencing microorganisms from sediment, higher content could offer more nutrition substrates,

380 which was meaningful to support greater microbial biomass (Wei et al., 2014).

381 Co-occurrence networks and keystone species of bacterial communities in ARs

382 Although the physical and chemical properties between water and sediment were fundamentally

383 different, the microbial communities are connected through the sedimentation of organic matters

384 (Lucie et al., 2011). To reveal the potential interactions among the bacterial communities in two

385 habitats, co-occurrence networks were used to promote our understanding of the microbiomes in

386 marine ecosystems (Berry and Widder, 2014). Species similarity between the water and sediment

387 networks was low (Jaccard $=11.8 \%$ ), and the similarity between the water network and total

388 bacterial network (33.1\%) was equal to that between the sediment network and total bacterial

389 network (31.5\%). These results indicated that habitats significantly affected the compositions of

390 microorganisms in the co-occurrence networks, which was consistent with Zhang et al. (2020a). 
391 A total of 47 OTUs were simultaneously observed in the three networks, and some played

392 important roles in ecosystems. For instance, family Woeseiaceae (OTU10090) covers a broad

393 physiological spectrum (Mußmann et al., 2017), which may promote plant survival by

394 participating in nitrogen and carbon cycling (Zhang et al., 2020b); family Methyloligellaceae

395 (OTU3417) was reported as an important host related to antibiotic resistance and metal resistance

396 (Zhang et al., 2021). Significant seasonality of the top five abundant OTUs for the networks was

397 exhibited, while the dissimilarities of their abundance among the four areas were relatively low

398 (Fig. 7 and Fig. 8). OTU18562 (family Planococcaceae) was the most abundant OTU in the total

399 network and water network, which showed evident temporal and spatial differences,

400 concurrently. OTU18562 affiliates to family Planococcaceae, which was correlated with the

401 decomposition of fertilizers (Suzuki et al., 2021). OTU17592 (family Moraxellaceae) had higher

402 abundance in RR and CR than in TA and AA in the total network and water network, indicating

403 positive relationships between OTU17592 and ARs existed. OTU18751 (family Microtrichales),

404 which showed the highest abundance in summer and lowest abundance in spring, played crucial

405 roles in hydrolyzing and utilizing complex organic matters (Li et al., 2021).

406 Keystone species are highly connected taxa in networks that play vital roles in maintaining

407 microbial community structures (Faust and Raes, 2012). The top ten keystone OTUs in the three

408 co-occurrence networks were significantly different. As reported, differences of key microbial

409 groups at ARs and open waters have also been studied (Zhu et al., 2020). The ranks of relative

410 abundance for the top ten keystone OTUs in the three network were low (Table S2). Two factors

411 could explain this phenomenon. On the one hand, it was suggested that abundant bacteria

412 contribute mostly to the biogeochemical cycles, while rare microbiomes might act to stabilize the

413 community (Shade et al., 2014; Genitsaris et al., 2015). Moreover, rare species may be disturbed

414 by the rapid changes of the environment (Shade et al., 2014). On the other hand, rare taxa could

415 considerably increase in abundance to respond the environmental disturbances; and these 
416 dynamics may be the reasons for their greater contributions to microbial communities (Caron and

417 Countway, 2009).

418 In general, relative to the important functions of keystone species in the community, the 419 discovery of these species evidently falls behind (Palit et al., 2020), which leads to a limited 420 understanding of microbial ecology. The abundance of the top five keystone OTUs in the water 421 network all showed similar seasonal variations (Fig. S6b), suggesting keystone species were 422 more consistent in response to the changes of environmental conditions than abundant species 423 (Fig. 7b). OTU525 belongs to family Flavobacteriaceae, which were reported as important

424 bacterial populations associated with algal blooms closely (Pavlovska et al., 2021). What's more, 425 the seasonality of the top five keystone OTUs in the sediment network was also significant (Fig. 426 S6c). Three keystone OTUs (OTU17592, OTU16870 and OTU17616) in the sediment network 427 had significantly higher abundance in RR than in other three areas (Fig. S7c), showing their 428 positive relationships with the deployment of rock reefs. These three keystone OTUs all affiliate 429 to order Pseudomonadales, class Gammaproteobacteria. As reported by Eswaran and 430 Khandeparker (2019), Pseudomonadales participated in mediating the degradation of 431 carbohydrates by producing $\beta$-Glucosidases in a tropical estuarine environment. Some other 432 keystone OTUs are also crucial in the particular ecological process. For instance, the abundance 433 of OTU7413 (family Rhodobacteraceae) ranked 137th in the water network (Table S2b), which 434 was regarded as the key member of the initial microbial biofilm in coastal seawater (Hila et al., 435 2013). OTU11572 and OTU8614 belong to family Thermoanaerobaculaceae, may play crucial 436 roles in nitrogen transformation in water (Wang et al., 2019a).

437

438 Conclusions

439 In the present study, we simultaneously profiled the temporal and spatial variabilities and 440 potential interaction patterns of bacterial communities in the water and sediment of ARs for the 
441 first time. Seasonal variations of bacterial community compositions were observed in the two

442 habitats, while spatial changes were only detected in the sediment. Bacterial communities in the

443 rock reef area were significantly different with other three areas, which indicating the deployment

444 of ARs impacted the bacterial communities in sediment. The potential correlations among

445 bacterial communities in the sediment were lowest in the three networks, suggesting less niche

446 overlap existed. The abundant and keystone species in the networks showed discordant variations

447 among four seasons and four areas, revealing that two types of species played different ecological

448 functions. As important artificial habitats in marine fisheries, our discoveries about ARs are

449 crucial to better comprehend the mechanisms of microbial ecology in artificial habitats, to

450 promote restoration efficiency, to improve biodiversity, and to recover the marine environment.

451 Particularly, marine microbial loops are comprehensive networks containing bacteria, archaea,

452 and eukaryotes, and further studies are suggested to reveal the interactions among these

453 microbiomes in artificial habitats.

454

455

456

457

458

459

460

461

462

463

464

465

466

467

468

469

470

471

472

473

474

\section{Acknowledgements}

This study was funded by the Project of Investigation of Fishery Resource of Marine Ranching from the Department of Agriculture and Rural Affairs of Shandong Province. We thank all scientific staff and crew members of Qingdao Longpan Company for their assistance in the surveys.

\section{References}

Abia A, Alisoltani A, Keshri J, Ubomba-Jaswa E. 2017. Metagenomic analysis of the bacterial communities and their functional profiles in water and sediments of the Apies River, South Africa, as a function of land use. Science of the Total Environment 616-617: 326-334. DOI 10.1016/j.scitotenv.2017.10.322

Agawin N, Duarte CM, Agustí S. 2000. Nutrient and temperature control of the contribution of picoplankton to phytoplankton biomass and production. Limnology and Oceanography 45(3): 591-600. DOI 10.4319/lo.2000.45.3.0591

Aleksandrov BG, Minicheva GG, Strikalenko TV. 2002. Ecological aspects of artificial reef construction using scrap tires. Russian Journal of Marine Biology 28(2): 120-126. DOI 10.1023/A:1015396512150

Anderson MJ. 2001. Permutation tests for univariate or multivariate analysis of variance and regression. Canadian Journal of Fisheries and Aquatic Sciences 58: 626-639. DOI: 10.1139/cjfas-58-3-626 
475

476

477

478

479

480

481

482

483

484

485

486

487

488

489

490

491

492

493

494

495

496

497

498

499

500

501

502

503

504

505

506

507

508

509

510

511

512

513

514

515

516

517

518

519

520

521

Balzano S, Abs E, Leterme SC. 2015. Protist diversity along a salinity gradient in a coastal lagoon. Aquatic Microbial Ecology 74(3): 263-277. DOI 10.3354/ame0174

Barberan A, Bates ST, Casamayor EO, Fierer N. 2012. Using network analysis to explore cooccurrence patterns in soil microbial communities. The ISME Journal 6: 343-351. DOI 10.1038/ismej.2011.119

Bell KS, Philp JC, Aw D, Christofi N. 1998. The genus Rhodococcus. Journal of Applied Microbiology 85(2): 195-210. DOI 10.1046/j.1365-2672.1998.00525.x

Berdjeb L, Parada A, Needham DM, Fuhrman JA. 2018. Short-term dynamics and interactions of marine protist communities during the spring-summer transition. The ISME Journal 12: 1907-1917. DOI 10.1038/s41396-018-0097-X

Berry D, Widder S. 2014. Deciphering microbial interactions and detecting keystone species with co-occurrence networks. Frontiers in Microbiology 5: 219. DOI 10.3389/fmicb.2014.00219

Boras JA, Sala MM, Vázquez-Domínguez E, Weinbauer MG, Vaqué D. 2010. Annual changes of bacterial mortality due to viruses and protists in an oligotrophic coastal environment (NW Mediterranean). Environmental Microbiology 11(5): 1181-1193. DOI 10.1111/j.1462-2920.2008.01849.x

Borcard D, Gillet F, Legendre P. 2011. Numerical Ecology with R. Springer. Gewerbestrasse, Switzerland.

Brandt LD, House CH. 2016. Marine subsurface microbial community shifts across a hydrothermal gradient in Okinawa Trough sediments. Archaea 2016: 2690329. DOI 10.1155/2016/2690329

Bunse C, Pinhassi J. 2017. Marine bacterioplankton seasonal succession dynamics. Trends in Microbiology 25(6): 494-505. DOI 10.1016/j.tim.2016.12.013

Caporaso J, Kuczynski J, Stombaugh J. 2010. QIIME allows analysis of high-throughput community sequencing data. Nature Methods 7: 335-336. DOI: 10.1038/nmeth.f.303

Caron DA, Countway PD. 2009. Hypotheses on the role of the protistan rare biosphere in a changing world. Aquatic Microbial Ecology 57(3): 227-238. DOI 10.3354/ame01352

Chen JL, Chuang CT, Jan RQ, Liu LC, Jan MS. 2013. Recreational benefits of ecosystem services on and around artificial reefs: a case study in Penghu, Taiwan. Ocean \& Coastal Management 85: 58-64. DOI 10.1016/j.ocecoaman.2013.09.005

Chen Q, Yuan H, Chen P. 2019. Short-term effects of artificial reef construction on the taxonomic diversity and eco-exergy of the macrobenthic faunal community in the pearl river estuary, China. Ecological indicators 98: 772-782. DOI 10.1016/j.ecolind.2018.12.001

Cheung MK, Wong CK, Chu KH, Kwan HS. 2018. Community structure, dynamics and interactions of bacteria, archaea and fungi in subtropical coastal wetland sediments. Scientific Reports 8: 14397. DOI: 10.1038/s41598-018-32529-5

Clarke KR. 1993. Nonparametric multivariate analyses of changes in community structure. Australian Journal of Ecology 18: 117-143. DOI: 10.1111/j.1442-9993.1993.tb00438.x

Davies CM, Evison LM. 1991. Sunlight and the survival of enteric bacteria in natural waters. Journal of Applied Microbiology 70(3): 265-74. DOI 10.1111/j.1365-2672.1991.tb02935.x.

Dmitry P, Julian H, Edwin KS Marcello P, Markus MN, Christian D, Christoph L, Heide LF. 2016. Utilizing the Jaccard index to reveal population stratification in sequencing data: a simulation study and an application to the 1000 Genomes Project. Bioinformatics 32(9): 13661372. DOI 10.1093/bioinformatics/btv752

Eleftheriou A. 2013. Methods for the study of marine benthos. John Wiley \& Sons Ltd. Sussex, UK. pp 82-84.

Peer] reviewing PDF | (2021:07:63738:2:0:NEW 3 Dec 2021) 
522

523

524

525

526

527

528

529

530

531

532

533

534

535

536

537

538

539

540

541

542

543

544

545

546

547

548

549

550

551

552

553

554

555

556

557

558

559

560

561

562

563

564

565

566

567

568

569
Espinoza-González O, Figueiras FG, Crespo BG, Teixeira IG, Castro CG. 2012. Autotrophic and heterotrophic microbial plankton biomass in the NW Iberian upwelling: seasonal assessment of metabolic balance. Aquatic Microbial Ecology 67(1): 77-89. DOI 10.3354/ame01584

Eswaran R, Khandeparker L. 2019. Seasonal variation in beta-glucosidase-producing culturable bacterial diversity in a monsoon-influenced tropical estuary. Environmental Monitoring and Assessment 191: 662. DOI 10.1007/s10661-019-7818-0

Fadeev E, Salter I, Schourup-Kristensen V, Nthig EM, Bienhold C. 2018. Microbial communities in the east and west Fram Strait during sea ice melting season. Frontiers in Marine Science 5: 429. DOI 10.3389/fmars.2018.00429

Fang GJ, Yu HL, Sheng HX, Tang YL, Liang ZL. 2021. Comparative analysis of microbial communities between water and sediment in Laoshan Bay marine ranching with varied aquaculture activities. Marine Pollution Bulletin 173: 112990. DOI:

10.1016/j.marpolbul.2021.112990

Faust K, Raes J. 2012. Microbial interactions: from networks to models. Nature Reviews Microbiology 10(8): 538-550. DOI 10.1038/nrmicro2832

Feng BW, Li XR, Wang JH, Hu ZY, Meng H, Xiang LY. 2009. Bacterial diversity of water and sediment in the Changjiang estuary and coastal area of the East China Sea. FEMS Microbiology Ecology 70(2): 80-92. DOI 10.1111/j.1574-6941.2009.00772.x

Figueiras FG, Teixeira IG, Froján M, Zúiga D, Castro CG. 2020. Seasonal variability in the microbial plankton community in a semienclosed bay affected by upwelling: the role of a nutrient trap. Frontiers in Marine Science 7: 578042. DOI 10.3389/fmars.2020.578042

Fournier B, Samaritani E, Frey B, Seppey C, Mitchell E. 2020. Higher spatial than seasonal variation in floodplain soil eukaryotic microbial communities. Soil Biology and Biochemistry 147: 107842. DOI 10.1016/j.soilbio.2020.107842

Genitsaris S, Monchy S, Viscogliosi E, Sime-Ngando T, Ferreira S, Christaki U. 2015. Seasonal variations of marine protist community structure based on taxon-specific traits using the Eastern English Channel as a model coastal system. FEMS Microbiology Ecology 91(5): fiv034. DOI 10.1093/femsec/fiv034

Hatosy SM, Martiny J, Sachdeva R, Steele J, Fuhrman JA, Martiny AC. 2013. Beta diversity of marine bacteria depends on temporal scale. Ecology 94(9): 1898-1904. DOI 10.1890/12-2125.1

Hila E, Gilad H, Meir A, Yehuda C, Dror M. Rhodobacteraceae are the key members of the microbial community of the initial biofilm formed in eastern Mediterranean coastal seawater. FEMS Microbiology Ecology 85(2): 348-357. DOI 10.1111/1574-6941.12122

Huang W, Chen X, Jiang X, Zheng B. 2017. Characterization of sediment bacterial communities in plain lakes with different trophic statuses. Microbiologyopen 6: e503. DOI 10.1002/mbo3.503

Jackson J, Kirby MX, Berger WH, Bjorndal KA, Botsford LW, Bourque BJ. 2001. Historical overfishing and the recent collapse of coastal ecosystems. Science 293: 629-638. DOI 10.1126/science.1059199

Janiak DS, Branson D. 2021. Impacts of habitat and predation on epifaunal communities from seagrass beds and artificial structures. Marine Environmental Research 163: 105225. DOI 10.1016/j.marenvres.2020.105225

Koldewey HJ, Curnick D, Harding S, Harrison LR, Gollock M. 2010. Potential benefits to fisheries and biodiversity of the Chagos Archipelago/British Indian Ocean Territory as a notake marine reserve. Marine Pollution Bulletin 60(11): 1906-1915. DOI

10.1016/j.marpolbul.2010.10.002 
570

571

572

573

574

575

576

577

578

579

580

581

582

583

584

585

586

587

588

589

590

591

592

593

594

595

596

597

598

599

600

601

602

603

604

605

606

607

608

609

610

611

612

613

614

615

616

Langille MG, Zaneveld J, Caporaso JG, McDonald D, Knights D, Reyes JA, Clemente JC, Burkepile DE, Thurber RL, Knight R, Beiko RG, Huttenhower C. 2013. Predictive functional profiling of microbial communities using 16S rRNA marker gene sequences. Nature Biotechnology 31(9): 814-821. DOI 10.1038/nbt.2676

Lee SY, Eom YB. 2016. Analysis of microbial composition associated with freshwater and seawater. Biomedical Science Letter 22: 150-159. DOI 10.15616/BSL.2016.22.4.150

Lee H, Heo Y, Kwon SL, Yoo Y, Kim D, Lee J, Kwon BO, Khim JS, Kim JJ. 2020. Environmental drivers affecting the bacterial community of intertidal sediments in the Yellow Sea. Science of The Total Environment 755: 142726. DOI 10.1016/j.scitotenv.2020.142726

Li J, Zheng L, Ye CB, Ni BS, Wang XZ, Liu H. 2021. Evaluation of an intermittent-aeration constructed wetland for removing residual organics and nutrients from secondary effluent: performance and microbial analysis. Bioresource Technology 329: 124897. DOI 10.1016/j.biortech.2021.124897

Lima JS, Zalmon IR, Love M. 2019. Overview and trends of ecological and socioeconomic research on artificial reefs. Marine Environmental Research 145: 81-96. DOI 10.1016/j.marenvres.2019.01.010

Lima JS, Atalah J, Sanchezjerez P, Zalmon IR. 2020. Evaluating the performance and management of artificial reefs using artificial reef multimetric index (ARMI). Ocean \& Coastal Management 198, 105350. DOI 10.1016/j.ocecoaman.2020.105350

Liu X, Hu HW, Liu YR, Xiao KQ, Cheng FS, Ji L. 2015. Bacterial composition and spatiotemporal variation in sediments of Jiaozhou Bay, China. Journal of Soils and Sediments 15(3): 732-744. DOI 10.1007/s11368-014-1045-7

Liu T, Zhang AN, Wang J, Liu S, Jiang X, Dang C. 2018. Integrated biogeography of planktonic and sedimentary bacterial communities in the Yangtze River. Microbiome 6(1): 16. DOI 10.1186/s40168-017-0388-X

Lucie Z, Amaral-Zettler LA, Fuhrman JA, Claire H, Huse SM, Mark W. 2011. Global patterns of bacterial beta-diversity in seafloor and seawater ecosystems. PloS One 6(9): e24570. DOI 10.1371/journal.pone.0024570

Mangot JF, Domaizon I, Taib N, Marouni N, Duffaud E, Bronner G. 2013. Short-term dynamics of diversity patterns: evidence of continual reassembly within lacustrine small eukaryotes. Environmental Microbiology 15(6): 1745-1758. DOI 10.1111/1462-2920.12065

Margesin R. 2009. Effect of temperature on growth parameters of psychrophilic bacteria and yeasts. Extremophiles 13(2): 257. DOI 10.1007/s00792-008-0213-3

Marquardt M, Vader A, Stübner EI, Reigstad M, Gabrielsen TM. 2016. Strong seasonality of marine microbial eukaryotes in a high-Arctic fjord (Isfjorden, West Spitsbergen). Applied and Environmental Microbiology 82(6): 1868-1880. DOI 10.1128/AEM.03208-15

Martin A, Thomas P, Rhena S. 2017. Identification of Cyanobacteria in a eutrophic coastal lagoon on the Southern Baltic Coast. Frontiers in Microbiology 8: 923. DOI 10.3389/fmicb.2017.00923

Mikhailov IS, Zakharova YR, Bukin YS, Galachyants YP, Petrova DP, Sakirko MV. 2019. Co-occurrence networks among bacteria and microbial eukaryotes of lake Baikal during a spring phytoplankton bloom. Microbial Ecology 77(1): 96-109. DOI 10.1007/s00248-0181212-2

Ming HX, Fan JF, Liu JW, Su J, Wan ZY, Wang YT, Li DW, Li MF, Shi TT, Jin Y, Huang HL, Song JX. 2021. Full-length 16S rRNA gene sequencing reveals spatiotemporal dynamics of bacterial community in a heavily polluted estuary, China. Environmental Pollution 275(2): 116567. DOI: 10.1016/j.envpol.2021.116567

Peer] reviewing PDF | (2021:07:63738:2:0:NEW 3 Dec 2021) 
617 Mohapatra M, Behera P, Ji YK, Rastogi G. 2020. Seasonal and spatial dynamics of

618 bacterioplankton communities in a brackish water coastal lagoon. Science of the Total

619 Environment 705: 134729. DOI 10.1016/j.scitotenv.2019.134729

620 Mußmann M, Pjevac P, Krüger K. 2017. Genomic repertoire of the Woeseiaceae/JTB255,

621

622

623

624

625

626

627

628

629

630

631

632

633

634

635

636

637

638

639

640

641

642

643

644

645

646

647

648

649

650

651

652

653

654

655

656

657

658

659

660

661

662

663 cosmopolitan and abundant core members of microbial communities in marine sediments. The ISME Journal 11: 1276-1281. DOI 10.1038/ismej.2016.185

Ng C, Toh TC, Chou LM. 2017. Artificial reefs as a reef restoration strategy in sedimentaffected environments: insights from long-term monitoring. Aquatic Conservation: Marine and Freshwater Ecosystems 2017: 1-10. DOI 10.1002/aqc.2755

Palit K, Das S. 2020. Community structure, taxonomic diversity and spatio-temporal variation of sediment and water bacteria in bhitarkanika mangrove ecosystem, India. International Journal of Environmental Science and Technology 18: 1147-1166. DOI 10.1007/s13762-020-02851-5

Pavlovska M, Prekrasna I, Dykyi E, Zotov A, Stoica E. 2021. Niche partitioning of bacterial communities along the stratified water column in the Black Sea. MicrobiologyOpen 10: e1195. DOI 10.1002/mbo3.1195

Pereira HM, Leadley PW, Proenca V, Alkemade R, Scharlemann J, Fernandez-Manjarres JF. 2010. Scenarios for global biodiversity in the 21st century. Science 330(6010): 1496-1501. DOI 10.1126/science.1196624

Perkins TL, Clements K, Baas JH, Jago CF, Jones DL, Malham SK, McDonald JE. 2014. Sediment composition influences spatial variation in the abundance of human pathogen indicator bacteria within an estuarine environment. PLoS One 9: e112951. DOI 10.1371/journal.pone.0112951

Pinhassi J, Gómez-Consarnau L, Alonso-Sáez L, Sala M, Vidal M, Pedrós-Alió C. 2006. Seasonal changes in bacterioplankton nutrient limitation and their effects on bacterial community composition in the NW Mediterranean Sea. Aquatic Microbial Ecology 44(3): 241252. DOI 10.3354/ame044241

Piwosz K., Calkiewicz J, Golebiewski M, Creer S. 2018. Diversity and community composition of pico- and nanoplanktonic protists in the Vistula river estuary (Gulf of Gdansk, Baltic Sea). Estuarine Coastal and Shelf Science 207: 242-249. DOI 10.1016/j.ecss.2018.04.013

Pommier T, Canbck B, Riemann L, Bostrm KH, Simu K, Lundberg P. 2007. Global patterns of diversity and community structure in marine bacterioplankton. Molecular Ecology 16(4): 867-880. DOI 10.1111/j.1365-294X.2006.03189.x

Qin C, Cn QA, Zhu W, Ma H, Pan W. 2019. Are habitat changes driving protist community shifts? a case study in Daya Bay, China. Estuarine Coastal and Shelf Science 227: 106356. DOI 10.1016/j.ecss.2019.106356

Scott ME, Smith JA, Lowry MB, Taylor MD, Suthers IM. 2015. The influence of an offshore artificial reef on the abundance of fish in the surrounding pelagic environment. Marine \& Freshwater Research 66: 429-437. DOI 10.1071/MF14064

Seaman WJ, Sprague LM. 1993. Artificial habitats for marine and freshwater fisheries. Fisheries Research 16(1): 89-92. DOI 10.1007/BF00043299

Shade A, Jones SE, Caporaso JG, Handelsman J, Knight R, Fierer N. 2014. Conditionally rare taxa disproportionately contribute to temporal changes in microbial diversity. mBio 5(4): e01371-14. DOI 10.1128/mBio.01371-14

Shen D, Jürgens K, Beier S. 2018. Experimental insights into the importance of ecologically dissimilar bacteria to community assembly along a salinity gradient. Environmental Microbiology 20(3): 1170-1184. DOI 10.1111/1462-2920.14059 
664 Sheng H, Tang Y, Wang X. 2018. Relationship between environmental factors and benthic

665

666

667

668

669

670

671

672

673

674

675

676

677

678

679

680

681

682

683

684

685

686

687

688

689

690

691

692

693

694

695

696

697

698

699

700

701

702

703

704

705

706

707

708

709

710 macroalgae communities of artificial reefs in Laoshan Bay. Indian Journal of Geo Marine Sciences 47(11): 2248-2254.

Shin PK, Cheung SG, Tsang TY, Wai HY. 2014. Ecology of artificial reefs in the subtropics. Advances in Marine Biology 68: 1-63. DOI 10.1016/B978-0-12-800169-1.00001-X

Shu W, Wang P, Zhang H, Ding M, Wu B. 2020. Seasonal and spatial distribution and assembly processes of bacterioplankton communities in a subtropical urban river. FEMS Microbiology Ecology 96: fiaa154. DOI 10.1093/femsec/fiaa154

Silverman MP, Munoz EF. 1975. Microbial metabolism and dynamic changes in the electrical conductivity of soil solutions: a method for detecting extraterrestrial life. Applied microbiology 28(6): 960-967. DOI 10.1128/AEM.28.6.960-967.1974

Smouse PE, Long JC, Sokal RR. 1986. Multiple regression and correlation extensions of the mantel test of matrix correspondence. Systematic Zoology 35(4), 627-632. DOI: $10.2307 / 2413122$

Soka S, Hutagalung RA, Yogiara AC. 2011. Population dynamic of Dendronephthya sp.associated bacteria in natural and artificial habitats. HAYATI Journal of Biosciences 18(2): 5760. DOI 10.4308/hjb.18.2.57

Sun P, Liu X, Tang Y, Cheng W, Sun R, Wang X. 2017. The bio-economic effects of artificial reefs: mixed evidence from Shandong, China. ICES Journal of Marine Science 74(8): 22392248. DOI 10.1093/icesjms/fsx058

Sun Y, Li X, Liu J, Yao Q, Jin J, Liu X. 2019. Comparative analysis of bacterial community compositions between sediment and water in different types of wetlands of Northeast China. Journal of Soil \& Sediments 19(7): 3083-3097. DOI 10.1007/s11368-019-02301-x

Suzuki K, Naoya K, Kota N, Rasit A, Naoki H. 2021. Impacts of application of calcium cyanamide and the consequent increase in soil $\mathrm{pH}$ on $\mathrm{N}_{2} \mathrm{O}$ emissions and soil bacterial community compositions. Biology and Fertility of Soils 57(2): 269-279. DOI 10.1007/s00374020-01523-3

State Bureau of Quality and Technical Supervision of China. 2007. GB/T 12763-2007 Specifications for oceanographic survey. China Standards Press, Beijing (in Chinese).

Steele JA, Countway PD, Xia L, Vigil PD, Beman JM, Kim DY, Chow CET, Sachdeva R, Jones AC, Schwalbach MS. 2011. Marine bacterial, archaeal and protistan association networks reveal ecological linkages. The ISME Journal 5(9): 1414-25. DOI 10.1038/ismej.2011.24

Sunagawa S, Coelho LP, Chaffron S, Kultima JR, Labadie K, Salazar G, Djahanschiri B, Zeller G, Mende DR, Alberti A, Cornejo-Castillo FM, Costea PI, Cruaud C, d'Ovidio F, Engelen S, Ferrera I, Gasol JM, Guidi L, Hildebrand F, Kokoszka F, Lepoivre C, LimaMendez G, Poulain J, Poulos BT, Royo-Llonch M, Sarmento H, Vieira-Silva S, Dimier C, Picheral M, Searson S, Kandels-Lewis S; Tara Oceans coordinators, Bowler C, de Vargas C, Gorsky G, Grimsley N, Hingamp P, Iudicone D, Jaillon O, Not F, Ogata H, Pesant S, Speich S, Stemmann L, Sullivan MB, Weissenbach J, Wincker P, Karsenti E, Raes J, Acinas SG, Bork P. 2015. Ocean plankton. Structure and function of the global ocean microbiome. Science 348(6237): 1261359. DOI 10.1126/science.1261359.

Tang YL, Wei SW, Yang MD, Wang XX, Zhao FF. 2022. Experimental investigation of local scour around artificial reefs in steady currents. Journal of Ocean University of China 21(2): 112. DOI 10.1007/s11802-022-4883-8

Timothy EE, Anne HB, John W. 2006. Fishing through marine food webs, Proceedings of the National Academy of Sciences 103(9): 3171-3175. DOI 10.1073/pnas.0510964103

Peer) reviewing PDF | (2021:07:63738:2:0:NEW 3 Dec 2021) 
711

712

713

714

715

716

717

718

719

720

721

722

723

724

725

726

727

728

729

730

731

732

733

734

735

736

737

738

739

740

741

742

743

744

745

746

747

748

749

750

751

752

753

754
Todd PA, Heery EC, Loke L, Thurstan RH, Kotze DJ, Swan C. 2019. Towards an urban marine ecology: characterizing the drivers, patterns and processes of marine ecosystems in coastal cities. Oikos 128(9): 1215-1242. DOI 10.1111/oik.05946

Verity PG, Smetacek V, Smetacek V, Smayda TJ, Smayda TJ. 2002. Status, trends and future of the marine pelagic ecosystem. Environmental Conservation 29(2): 207-237. DOI 10.1017/S0376892902000139

Wang M, Xiong WG, Zou Y, Lin MX, Zhou Q, Xie XY, Sun YX. 2019a. Evaluating the net effect of sulfadimidine on nitrogen removal in an aquatic microcosm environment. Environmental Pollution 248: 1010-1019. DOI 10.1016/j.envpol.2019.02.048

Wang X, Liu L, Zhao L, Xu H, Zhang X. 2019b. Assessment of dissolved heavy metals in the Laoshan Bay, China. Marine Pollution Bulletin 149: 110608. DOI 10.1016/j.marpolbul.2019.110608

Wang Y, Sun J, Fang E, Guo B, Dai Y, Gao Y, Wang H, Zhang X, Xu X, Yu Y, Liu K. 2019c. Impact of artificial reefs on sediment bacterial structure and function in Bohai Bay. Canadian Journal of Microbiology 65(3): 191-200. DOI 10.1139/cjm-2018-0157.

Wei H, Guenet B, Vicca S, Nunan N, Asard H, AbdElgawad H, Shen WJ, Janssens IA. 2014. High clay content accelerates the decomposition of fresh organic matter in artificial soils. Soil Biology \& Biochemistry 77(7): 100-108. DOI 10.1016/j.soilbio.2014.06.006

Williams-Grove LJ, Szedlmayer ST. 2017. Depth preferences and three-dimensional movements of red snapper, Lutjanus campechanus, on an artificial reef in the Northern Gulf of Mexico. Fisheries Research 190: 61-70. DOI 10.1016/j.fishres.2017.01.003

Wilms R, Kopke B, Sass H, Chang TS, Cypionka H, Engelen B. 2006. Deep biosphere-related bacteria within the subsurface of tidal flat sediments. Environmental Microbiology 8 (4): 709719. DOI 10.1111/j.1462-2920.2005.00949.x.

Woo J, Kim D, Yoon HS, Na WB. 2014. Characterizing Korean general artificial reefs by drag coefficients. Ocean Engineering 82: 105-114. DOI 10.1016/j.oceaneng.2014.02.025

Xu M, Yang XY, Song XJ, Xu KD, Yang LL. 2021. Seasonal analysis of artificial oyster reef ecosystems: implications for sustainable fisheries management. Aquaculture International 29(1): 167-192. DOI 10.1007/s10499-020-00617-X

Yang X, Lin C, Song X, Xu M, Yang H. 2019. Effects of artificial reefs on the meiofaunal community and benthic environment - a case study in Bohai Sea, China. Marine Pollution Bulletin 140: 179-187. DOI 10.1016/j.marpolbul.2018.12.031

Ye W, Liu X, Lin S, Tan J, Pan J, Li D, Yang H. 2009. The vertical distribution of bacterial and archaeal communities in the water and sediment of Lake Taihu. FEMS Microbiology Ecology 70(2): 107-120. DOI: 10.1111/j.1574-6941.2009.00761.x

Ye Q, Liu J, Du J, Jing Z. 2016. Bacterial diversity in submarine groundwater along the coasts of the Yellow Sea. Frontiers in Microbiology 6: 1519. DOI 10.3389/fmicb.2015.01519

Zentgraf B, Hedlich R, Gwenner C, Uyen NV, Thao NN. 1992. Isolation and characterization of thermophilic bacteria from natural and artificial habitats. Acta Biotechnologica 12(5): 397403. DOI 10.1002/abio.370120507

Zhang C, Liu Q, Li X, Wang MA, Yang J, Xu J, Jiang Y. 2020a. Spatial patterns and cooccurrence networks of microbial communities related to environmental heterogeneity in deepsea surface sediments around Yap Trench, Western Pacific Ocean. Science of The Total Environment 759: 143799. DOI 10.1016/j.scitotenv.2020.143799. 
755

756

757

758

759

760

761

762

763

764

765

766

767

768

769

770
Zhang X, Zhao C, Yu S, Jiang Z, Huang X. 2020b. Rhizosphere microbial community structure is selected by habitat but not plant species in two tropical seagrass beds. Frontiers in Microbiology 11: 161. DOI 10.3389/fmicb.2020.00161

Zhang N, Juneau, P, Huang R, He ZL, Sun B, Zhou JZ, Liang YT. 2021. Coexistence between antibiotic resistance genes and metal resistance genes in manure-fertilized soils. Geoderma 382: 114760. DOI 10.1016/j.geoderma.2020.114760

Zhao ZL, Jiang JW, Pan YJ, Dong Y, Zhou C, Zhang GH, Gao S, Sun HJ, Guan XY, Wang B, Xiao Y, Zhou ZC. 2020. Temporal dynamics of bacterial communities in the water and sediments of sea cucumber (Apostichopus japonicus) culture ponds. Aquaculture 528: 735498. DOI 10.1016/j.aquaculture.2020.735498

Zhu W, Qin C, Ma H, Xi S, Li C. 2020. Response of protist community dynamics and cooccurrence patterns to the construction of artificial reefs: A case study in Daya Bay, China. Science of The Total Environment 742: 140575. DOI 10.1016/j.scitotenv.2020.140575.

Zorz J, Willis C, Comeau AM, Langille M, Johnson CL, Li WKW. 2019. Drivers of regional bacterial community structure and diversity in the Northwest Atlantic Ocean. Frontiers in Microbiology 10: 281. DOI 10.3389/fmicb.2019.00281 
Figure 1

Seasonal change of Shannon diversity (mean \pm SD) of bacterial communities in the two habitats of artificial reefs.

Means with different letter (lowercase letters for water samples, capital letters for sediment samples) are significantly different with $\mathrm{P}$ value $<0.05$.

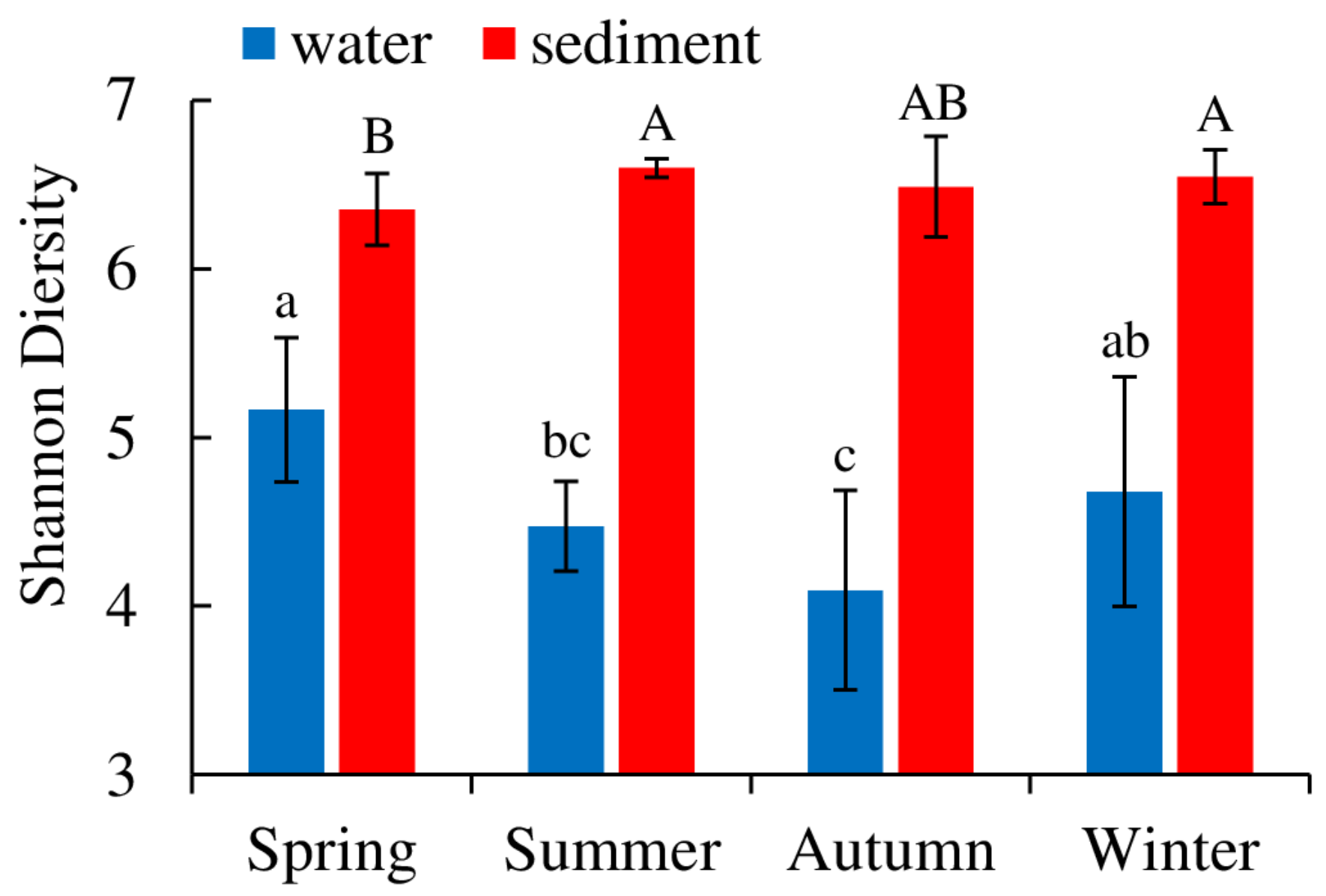


Figure 2

Relative abundance of bacterial communities at phylum levels in the two habitats and four seasons of artificial reefs.

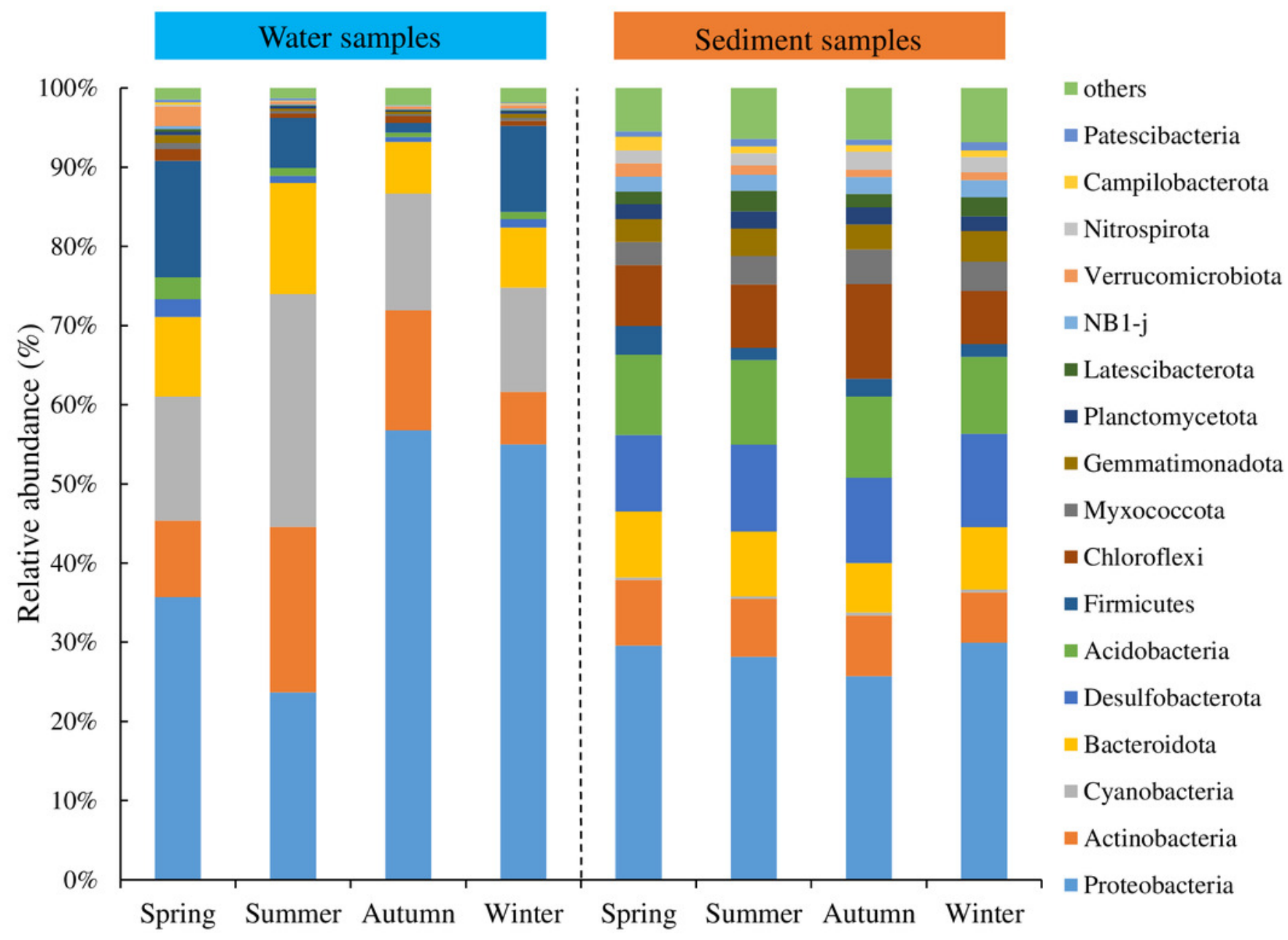


Figure 3

Principal coordinates analysis (PCOA) plots of bacterial communities in the water and sediment of artificial reefs.

R: the test statistical significance of analysis of similarities (ANOSIM); P: statistical significance value at $\alpha=0.05$ level.

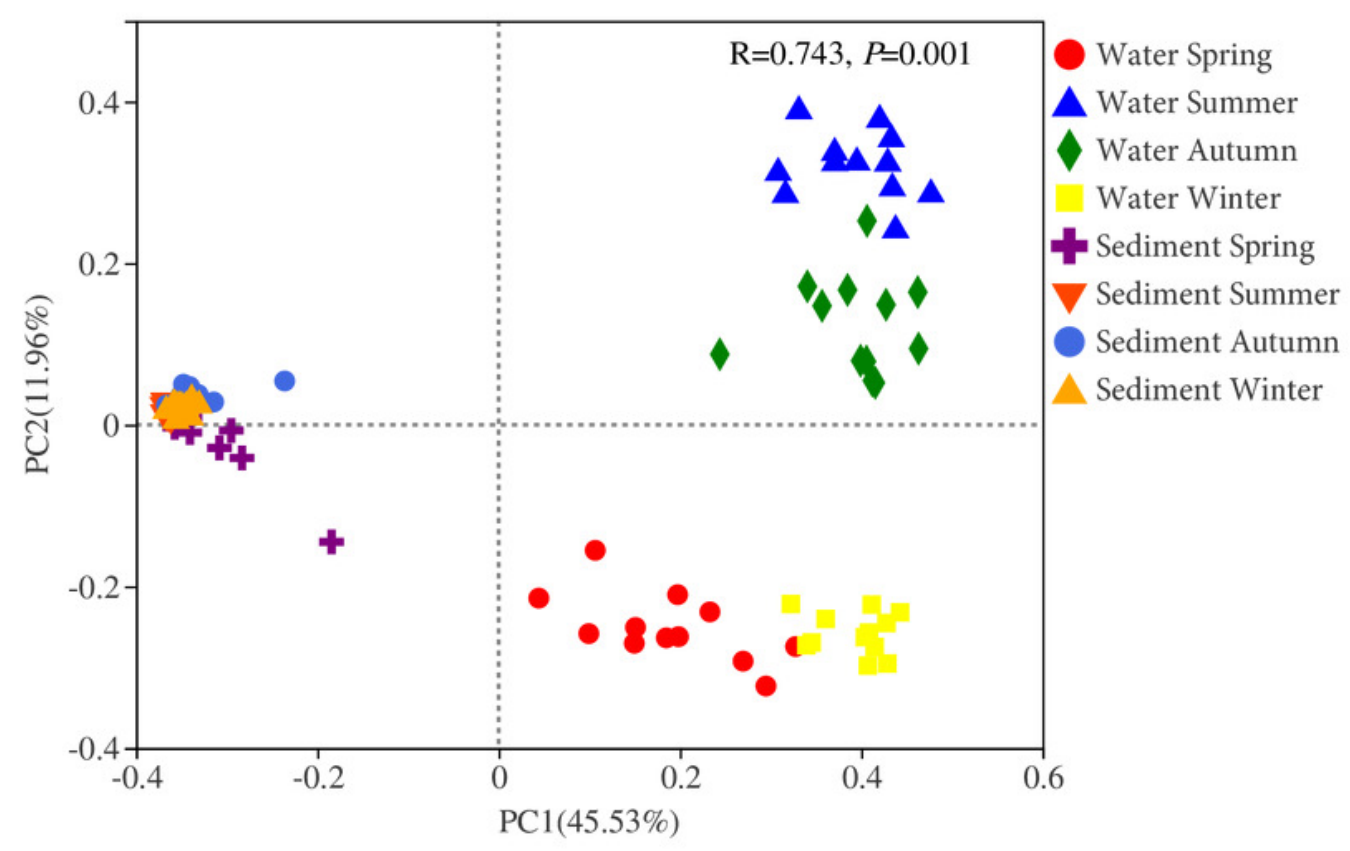


Figure 4

Seasonal variations of bacterial communities among samples in the water and sediment using Bray-Curtis dissimilarity.

Means with different letter (lowercase letters for water samples, capital letters for sediment samples) are significantly different with $P$ value $<0.05$.

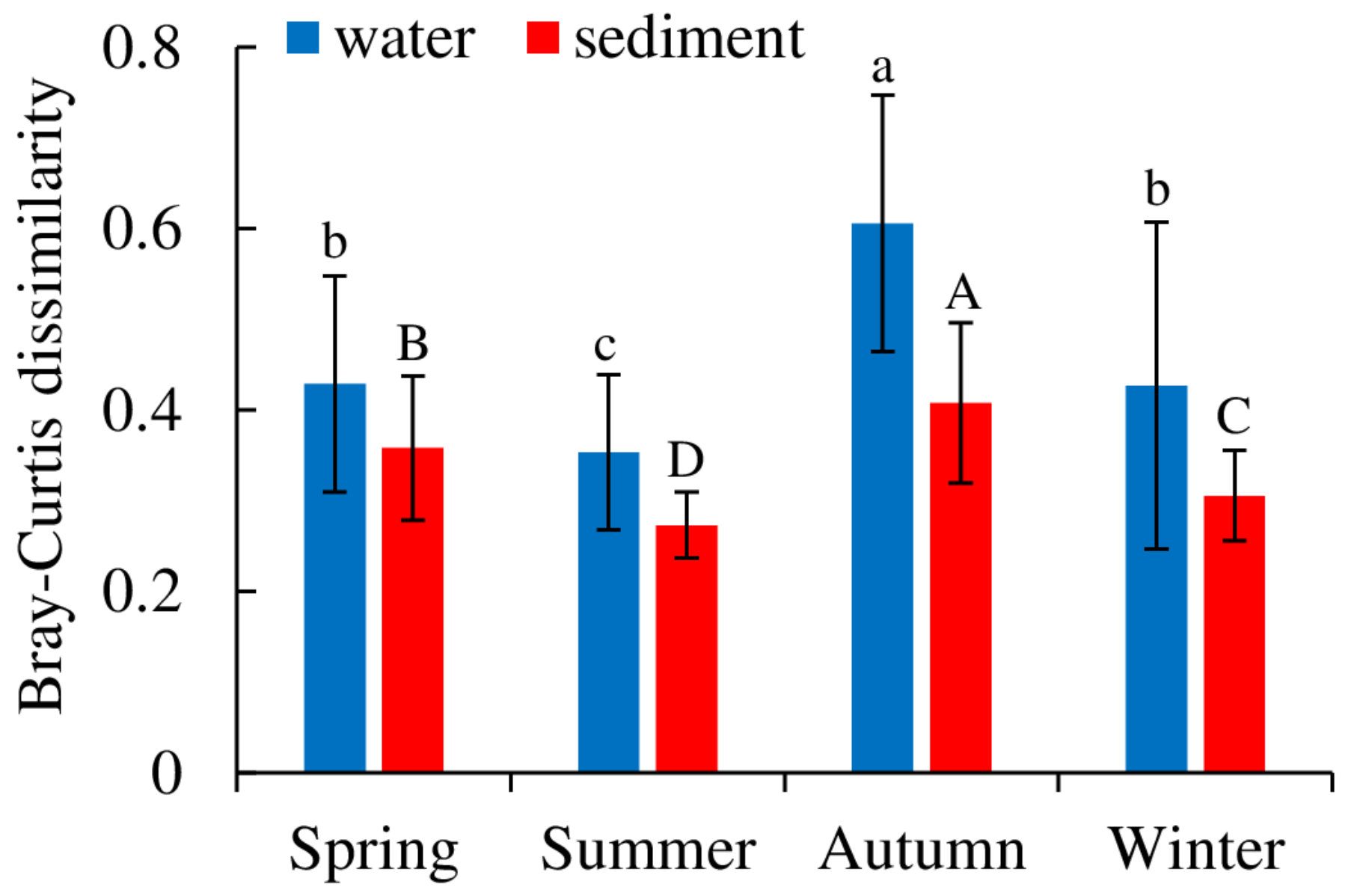




\section{Figure 5}

Heatmap of top abundant OTUs of bacterial communities with environmental factors in the (a) water and (b) sediment of artificial reefs.

The cluster trees were analyzed to show the similarity of OTUs using Bray-Curtis distance. Asterisks represent significant correlations between bacterial OTUs and environmental factors at the following $\alpha$ levels: $*=0.05, * *=0.01, * * *=0.001$. Environmental factors: temperature (Temp); transparency (Trans); chemical oxygen demand (COD); active silicate $\left(\mathrm{SiO}_{3}\right)$; suspended particulate materials (SPM); total organic carbon (TOC); ammonium $\left(\mathrm{NH}_{4^{-}}\right.$ $\mathrm{N})$; depth (Dep); chlorophyll-a (Chla); dissolved oxygen (DO); nitrite ( $\left.\mathrm{NO}_{2}-\mathrm{N}\right)$; turbidity (Turb); active phosphate $\left(\mathrm{PO}_{4}\right)$; electrical conductivity $(\mathrm{EC})$; water content $(\mathrm{WC})$; salinity (Sal); mean particle sizes (Par); organic matter content (OM); sediment bulk density (BD); mud content (MC). 
(a)

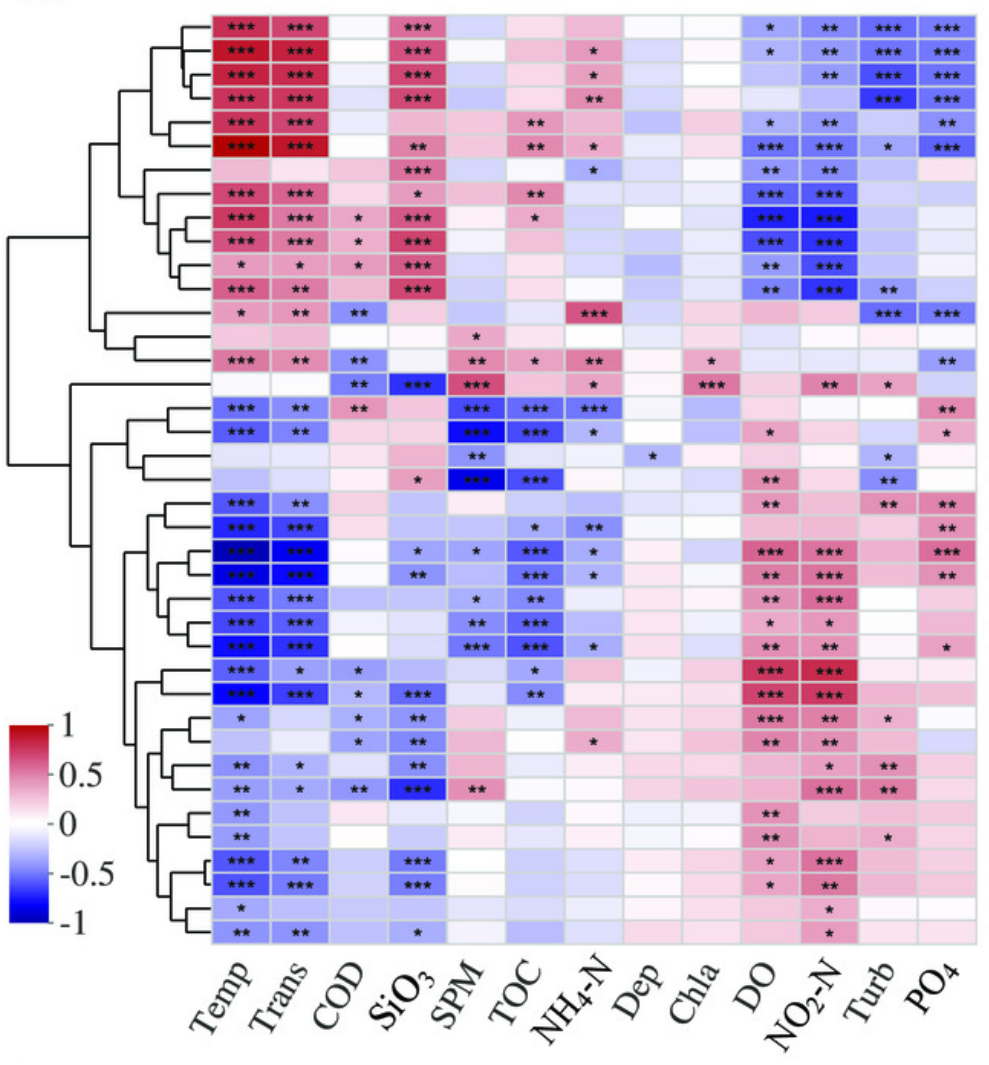

(b)

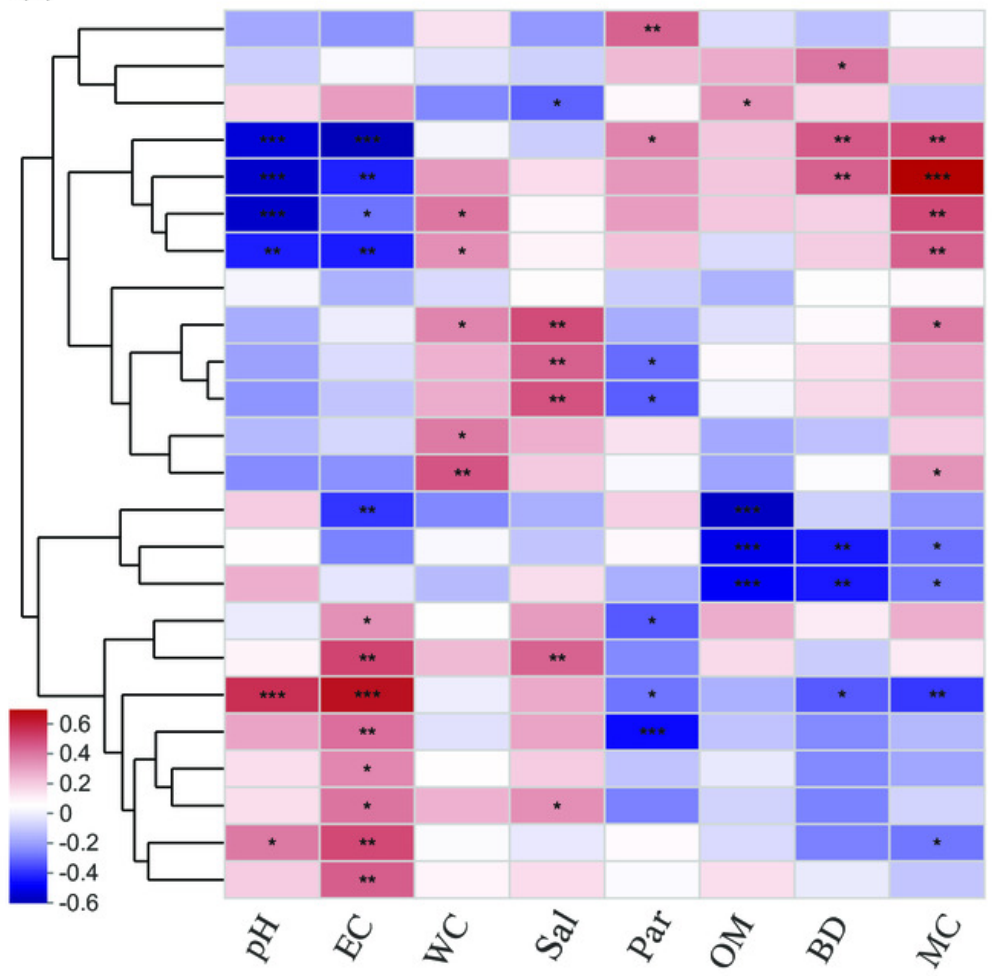

Class

OTU17369 Alphaproteobacteria

OTU16031 Cyanobacteriia

OTU1 8022 Acidimicrobiia

OTU18460 Cyanobacteriia

OTU14763 Cyanobacteriia

OTU16379 Gammaproteobacteria

OTU16046 Alphaproteobacteria

OTU18180 Actinobacteria

OTU17767 Gammaproteobacteria

OTU16371 Gammaproteobacteria

OTU15592 Gammaproteobacteria

OTU18053 Gammaproteobacteria

OTU18466 Actinobacteria

OTU14778 Bacilli

OTU18546 Acidimicrobiia

OTU16727 Gammaproteobacteria

OTU17917 Gammaproteobacteria

OTU14911 Acidimicrobiia

OTU16076 Gammaproteobacteria

OTU17592 Gammaproteobacteria

OTU18494 Cyanobacteriia

OTU19453 Alphaproteobacteria

OTU16155 Gammaproteobacteria

OTU17521 Alphaproteobacteria

OTU19164 Gammaproteobacteria

OTU18514 Gammaproteobacteria

OTU17166 Actinobacteria

OTU18450 Alphaproteobacteria

OTU18562 Bacilli

OTu17239 Bacill

OTU18468 Bacill

OTU10090 Gammaproteobacteria OTU17616 Gammaproteobacteria OTU16870 Gammaproteobacteria OTU15105 Cyanobacteriia

OTU19096 Cyanobacteriia

OTU16224 Gammaproteobacteria

\section{Class}

OTU3902 Gammaproteobacteria

OTU13814 Polyangia

OTU6550 Anaerolineae

OTU6409 Desulfobulbia

OTU9361 Gammaproteobacteria

OTU14579 Gammaproteobacteria

OTU12291 Gammaproteobacteria

OTU13137 Desulfobulbia

OTU13914 Gammaproteobacteria

OTU11572 Thermoanaerobaculia

OTU956 Desulfobacteria

OTU10090 Gammaproteobacteria

OTU16612 Bacteroidia

OTU13624 Campylobacteria

OTU525 Bacteroidia

OTU17166 Actinobacteria

OTU10279 Thermodesulfovibrionia

OTU9985 PAUC43f_marine_benthic_group

OTU3417 Alphaproteobacteria

OTU3621 Syntrophobacteria

OTU4433 Alphaproteobacteria

OTU4443 Alphaproteobacteria

OTU8614 Thermoanaerobaculia

OTU5350 Alphaproteobacteria 


\section{Figure 6}

Co-occurrence networks built from abundant bacterial OTUs in the water and sediment of artificial reefs.

Nodes are colored at (a) habitats and (b) phylum levels. Edges with $|r| \geq 0.8$ and $P \leq 0.001$ are shown in the networks. Positive and negative lines are represented by solid lines and dotted lines, respectively.

(a)

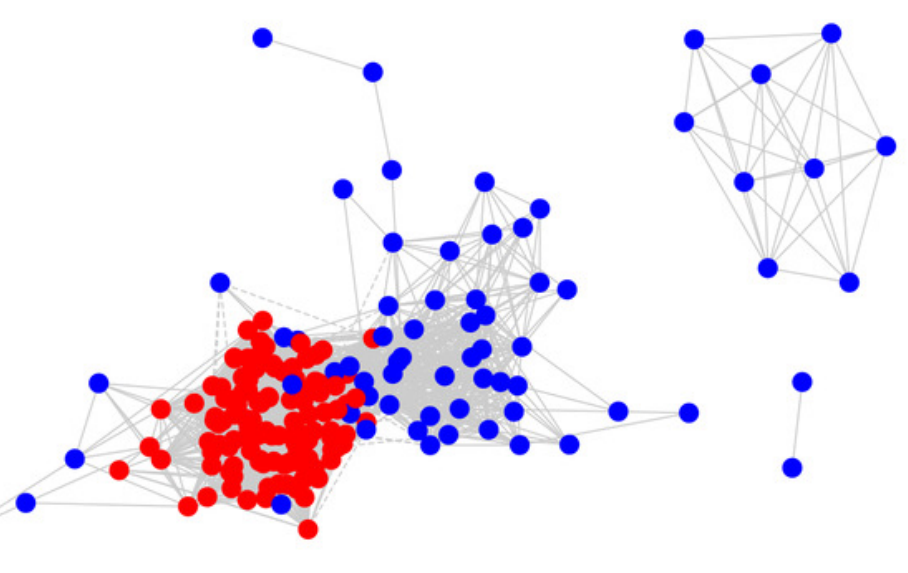

(b)

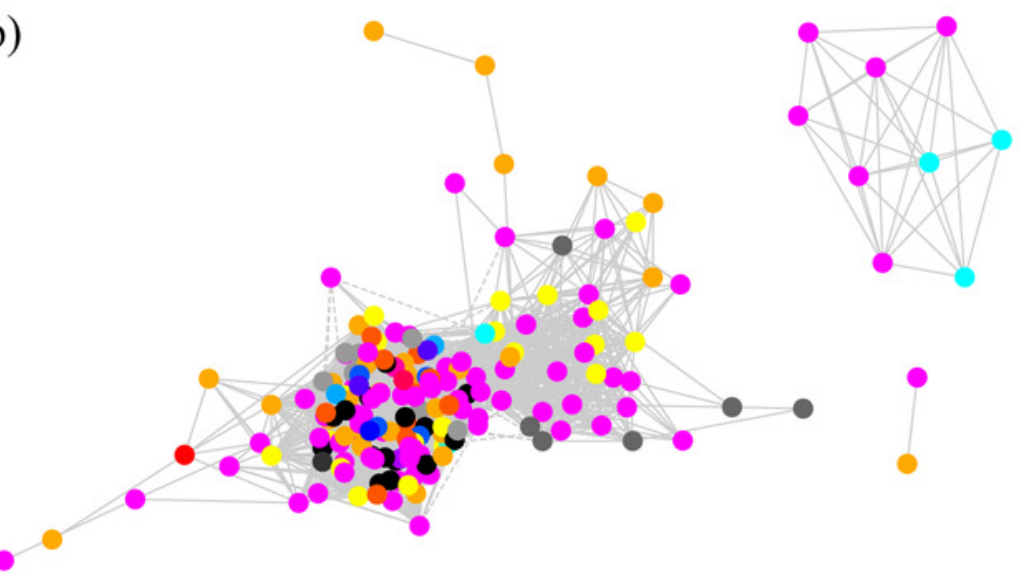

Sediment samples

Water samples

Acidobacteriota

Actinobacteriota

Bacteroidata

Campilobacterota

Chloroflexi

Cyanobacteria

Dadabacteria

Desulfobacterota

Firmicutes

Gemmatimonadota

Myxococcota

Nitrospinota

Nitrospirota

Planctomycetota

Proteobacteria

SAR324_cladeMarine_group_B

Schekmanbacteria

Verrucomicrobiota 


\section{Figure 7}

Seasonal changes of the relative abundance for the top five abundant OTUs of the cooccurrence networks in the (a) water and sediment, (b) water and (c) sediment of artificial reefs.

Four seasons: spring (SPR); summer (SUM); autumn (AUT); winter (WIN). 

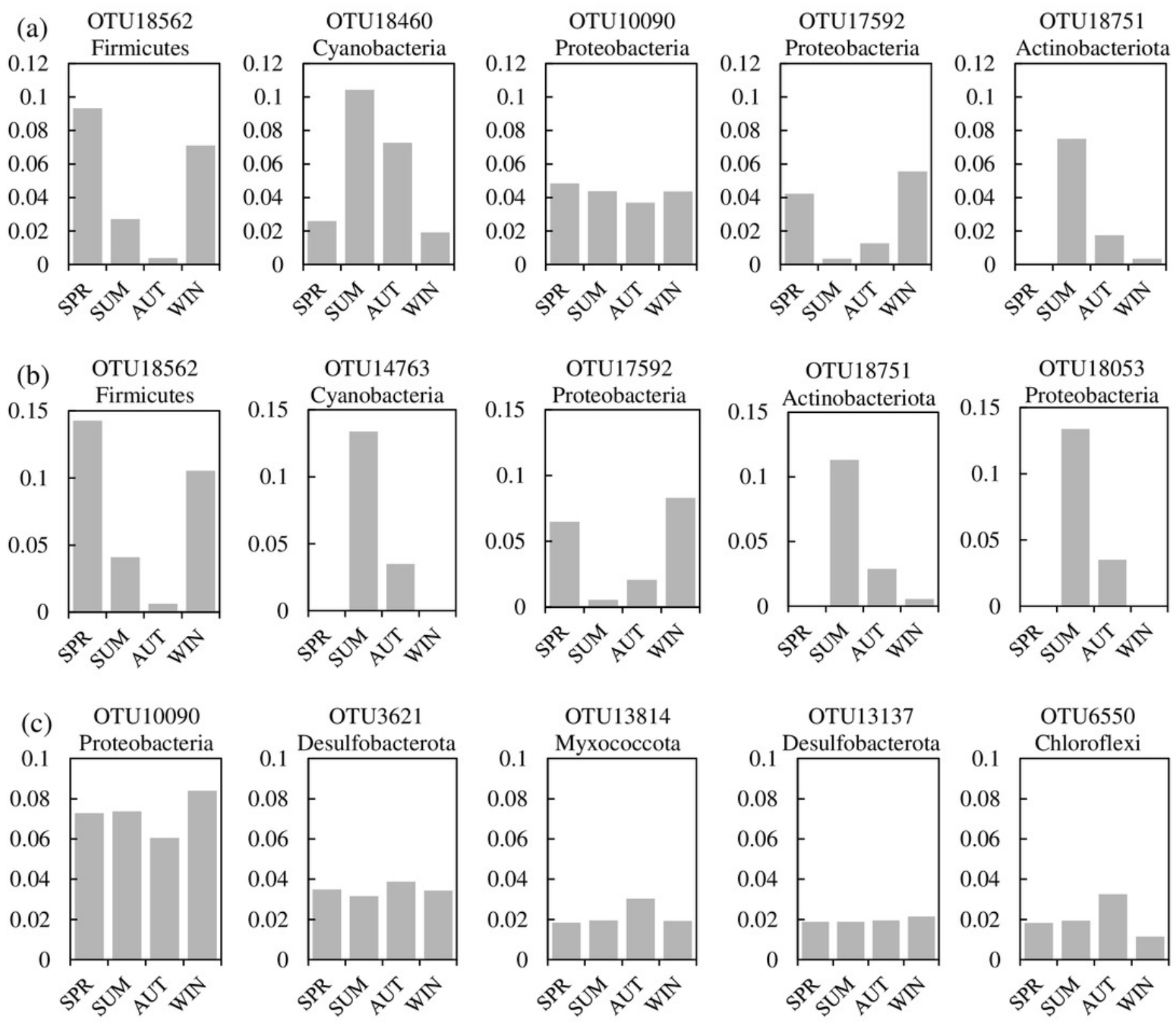
Figure 8

Variations of the relative abundance for the top five abundant OTUs among four sampling areas of the co-occurrence networks in the (a) water and sediment, (b) water and (c) sediment of artificial reefs (ARs).

Four sampling areas in ARs: rock reefs (RR), transition areas (TA), concrete reefs (CR) and adjacent areas (AA).
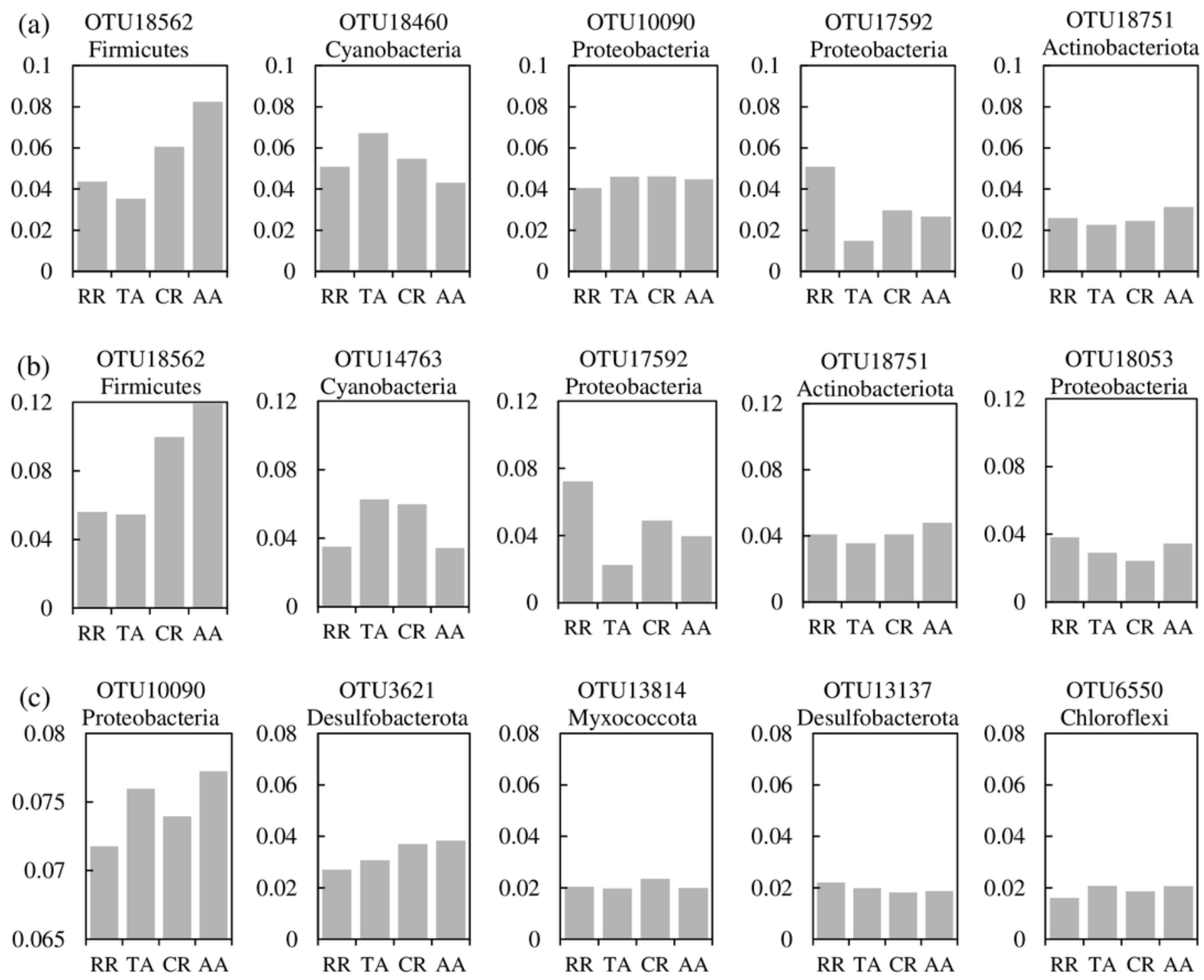


\section{Table $\mathbf{1}$ (on next page)}

Number of OTUs and alpha diversity indices in the water and sediment of artificial reefs for four seasons.

Seasonality $P$ : statistical difference among four seasons; Water-Sediment $P$ : statistical

difference between water and sediment samples. Significant difference was at $\alpha=0.05$ level. 
1

\begin{tabular}{|c|c|c|c|c|c|c|c|c|c|c|c|c|}
\hline \multirow[b]{2}{*}{ Season } & \multicolumn{2}{|c|}{ OTUs } & \multicolumn{2}{|c|}{ Shannon } & \multicolumn{2}{|c|}{ Simpson } & \multicolumn{2}{|c|}{ Ace } & \multicolumn{2}{|c|}{ Chao 1} & \multicolumn{2}{|c|}{ Coverage } \\
\hline & $\begin{array}{c}\text { Wate } \\
\mathbf{r}\end{array}$ & Sediment & $\begin{array}{c}\text { Wate } \\
\mathbf{r}\end{array}$ & Sediment & $\begin{array}{c}\text { Wate } \\
\mathbf{r}\end{array}$ & Sediment & $\begin{array}{c}\text { Wate } \\
\mathbf{r}\end{array}$ & Sediment & $\begin{array}{c}\text { Wate } \\
\mathbf{r}\end{array}$ & Sediment & $\begin{array}{c}\text { Wate } \\
\mathbf{r}\end{array}$ & Sediment \\
\hline Spring & 1726 & 2823 & 5.16 & 6.35 & 0.030 & 0.008 & 4742 & 6875 & 3349 & 5111 & 0.95 & 0.93 \\
\hline Summer & 1227 & 3056 & 4.47 & 6.60 & 0.040 & 0.005 & 3148 & 7210 & 2309 & 5408 & 0.97 & 0.92 \\
\hline Autumn & 984 & 3030 & 4.09 & 6.49 & 0.075 & 0.006 & 2665 & 7373 & 1936 & 5439 & 0.97 & 0.92 \\
\hline Winter & 1273 & 3103 & 4.68 & 6.55 & 0.045 & 0.006 & 3765 & 7490 & 2609 & 5584 & 0.97 & 0.92 \\
\hline Seasonality $P$ & 0.001 & 0.492 & 0.001 & 0.322 & 0.019 & 0.030 & 0.001 & 0.055 & 0.001 & 0.124 & 0.001 & 0.136 \\
\hline Water-Sediment $P$ & \multicolumn{2}{|c|}{0.004} & \multicolumn{2}{|c|}{0.005} & \multicolumn{2}{|c|}{0.025} & \multicolumn{2}{|c|}{0.007} & \multicolumn{2}{|c|}{0.005} & \multicolumn{2}{|c|}{0.011} \\
\hline
\end{tabular}

2 


\section{Table 2 (on next page)}

The effects of habitat, season and site on bacterial communities (OTU level) based on PERMANOVA and ANOSIM. Interaction effects were only calculated by PERMANOVA.

$F$ : the test statistical significance of Permutational multivariate analysis of variance (PERMANOVA); $R$ : the test statistical significance of analysis of similarities (ANOSIM); $P$ : statistical significance value at $\alpha=0.05$ level. 
1

\begin{tabular}{|c|c|c|c|c|c|}
\hline \multirow{2}{*}{ Habitat } & \multirow{2}{*}{ Effect } & \multicolumn{2}{|c|}{ PERMANOVA } & \multicolumn{2}{|c|}{ ANOSIM } \\
\hline & & $\boldsymbol{F}$ & $P$ & $\boldsymbol{R}$ & $\boldsymbol{P}$ \\
\hline \multirow{7}{*}{ Total } & Habitat & 73.951 & 0.001 & 0.89 & 0.001 \\
\hline & Season & 4.880 & 0.001 & 0.12 & 0.001 \\
\hline & Area & 0.463 & 0.973 & 0.02 & 0.862 \\
\hline & Habitat $\times$ Season & 28.950 & 0.001 & - & - \\
\hline & Habitat $\times$ Area & 11.096 & 0.001 & - & - \\
\hline & Season $\times$ Area & 1.218 & 0.139 & - & - \\
\hline & Habitat $\times$ Season $\times$ Area & 8.146 & 0.001 & - & - \\
\hline \multirow{3}{*}{ Water } & Season & 17.364 & 0.001 & 0.820 & 0.001 \\
\hline & Area & 0.438 & 0.999 & 0.060 & 0.994 \\
\hline & Season $\times$ Area & 4.172 & 0.001 & - & - \\
\hline \multirow{3}{*}{ Sediment } & Season & 2.905 & 0.001 & 0.227 & 0.001 \\
\hline & Area & 2.163 & 0.001 & 0.133 & 0.001 \\
\hline & Season $\times$ Area & 2.689 & 0.001 & - & - \\
\hline
\end{tabular}

2 


\section{Table 3 (on next page)}

Relationships between bacterial community and environmental factors based on the Mantel test and partial Mantel test.

$r$ : the test statistical significance of Mantel test and partial Mantel test; $P$ : statistical significance value at $\alpha=0.05$ level. Environmental factors: nitrite $\left(\mathrm{NO}_{2}-\mathrm{N}\right)$; temperature (Temp); transparency (Trans); active phosphate $\left(\mathrm{PO}_{4}\right)$; dissolved oxygen (DO); active silicate $\left(\mathrm{SiO}_{3}\right)$; chemical oxygen demand (COD); mud content (MC). 
1

\begin{tabular}{|c|c|c|c|c|c|}
\hline \multicolumn{3}{|c|}{ Water } & \multicolumn{3}{|c|}{ Sediment } \\
\hline Factor & $\mathbf{r}$ & $P$ & Factor & $\mathbf{r}$ & $P$ \\
\hline Total & 0.294 & 0.001 & Total & 0.145 & 0.018 \\
\hline $\mathrm{NO}_{2}-\mathrm{N}$ & 0.414 & 0.001 & $\mathrm{MC}$ & 0.125 & 0.050 \\
\hline Temp & 0.346 & 0.001 & & & \\
\hline Trans & 0.287 & 0.001 & & & \\
\hline $\mathrm{PO}_{4}$ & 0.215 & 0.003 & & & \\
\hline DO & 0.181 & 0.004 & & & \\
\hline $\mathrm{SiO}_{3}$ & 0.115 & 0.023 & & & \\
\hline COD & 0.141 & 0.039 & & & \\
\hline
\end{tabular}

2

3 